OPEN ACCESS

Edited by:

Chang-Jer Wu,

National Taiwan Ocean University,

Taiwan

Reviewed by:

Balaji Banoth,

St. Jude Children's Research Hospital,

United States

Usama Ashraf,

Stanford University, United States

*Correspondence:

Tsung-Hsien Chang

changth@mail.ndmctsgh.edu.tw

Kuen-Jer Tsai

kitsai@mail.ncku.edu.tw

Specialty section:

This article was submitted to

Viral Immunology,

a section of the journal

Frontiers in Immunology

Received: 05 August 2021 Accepted: 08 November 2021

Published: 25 November 2021

Citation:

Jan M-W, Su H-L, Chang T-H and Tsai K-J (2021) Characterization of

Pathogenesis and Inflammatory

Responses to Experimental

Parechovirus Encephalitis.

Front. Immunol. 12:753683.

doi: 10.3389/fimmu.2021.753683

\section{Characterization of Pathogenesis and Inflammatory Responses to Experimental Parechovirus Encephalitis}

\author{
Ming-Wei Jan ${ }^{1,2}$, Hong-Lin $\mathrm{Su}^{3}$, Tsung-Hsien Chang $^{4 *}$ and Kuen-Jer Tsai ${ }^{1,5 *}$ \\ 1 Institute of Clinical Medicine, College of Medicine, National Cheng Kung University, Tainan, Taiwan, ${ }^{2}$ Department of Medical \\ Education and Research, Kaohsiung Veterans General Hospital, Kaohsiung, Taiwan, ${ }^{3}$ Department of Life Sciences, \\ Agriculture Biotechnology Center, National Chung-Hsing University, Taichung, Taiwan, ${ }^{4}$ Department and Graduate Institute \\ of Microbiology and Immunology, National Defense Medical Center, Taipei, Taiwan, ${ }^{5}$ Research Center of Clinical Medicine, \\ National Cheng Kung University Hospital, College of Medicine, National Cheng Kung University, Tainan, Taiwan
}

Human parechovirus type 3 (PeV-A3) infection has been recognized as an emerging etiologic factor causing severe nerve disease or sepsis in infants and young children. But the neuropathogenic mechanisms of PeV-A3 remain unknown. To understand the pathogenesis of PeV-A3 infection in the neuronal system, PeV-A3-mediated cytopathic effects were analyzed in human glioblastoma cells and neuroblastoma cells. PeV-A3 induced interferons and inflammatory cytokine expression in these neuronal cells. The pronounced cytopathic effects accompanied with activation of death signaling pathways of apoptosis, autophagy, and pyroptosis were detected. A new experimental disease model of parechovirus encephalitis was established. In the disease model, intracranial inoculation with PeV-A3 in C57BL/6 neonatal mice showed body weight loss, hindlimb paralysis, and approximately 20\% mortality. PeV-A3 infection in the hippocampus and cortex regions of the neonatal mouse brain was revealed. Mechanistic assay supported the in vitro results, indicating detection of PeV-A3 replication, inflammatory cytokine expression, and death signaling transduction in mouse brain tissues. These in vitro and in vivo studies revealed that the activation of death signaling and inflammation responses is involved in PeV-A3-mediated neurological disorders. The present results might account for some of the PeV-A3-associated clinical manifestations.

Keywords: parechovirus A3, cytopathic effect, inflammation, neuronal diseases, infectious model

\section{INTRODUCTION}

Human parechovirus (PeV-A) is a 28-nm diameter, non-enveloped, positive-sense, signal-stranded RNA virus that belongs to the Picornaviridae family (1). PeV-A was first isolated from a diarrhea specimen and was originally classified as echoviruses 22 and 23 in 1956 (2). Then in view of its nucleotide sequence in replication and translation elements being different from other members of the genus Enterovirus, the virus was reclassified as Parechovirus, and echoviruses 22 and 23 were e-named PeV-A1 
and PeV-A2, respectively (3-5). At present, 19 types PeV-A (PeV$\mathrm{A} 1 \sim \mathrm{PeV}-\mathrm{A} 19)$ have been reported and recognized on the basis of their viral protein 1 (VP1) sequences (6).

$\mathrm{PeV}-\mathrm{A}$ is a widespread viral pathogen that affects children's health, causing gastroenteritis, respiratory disease, or severe nerve disease in children of younger age (7). The outbreak of adult PeV-A type 3 (PeV-A3)-associated myalgia was reported in Japan, suggesting that $\mathrm{PeV}$-A might be a new disease pathogen in adult (8). Owing to poor growth of PeV-A in culture as well as laborious and time-consuming technique involved, it is not routinely detected in most clinical laboratories $(9,10)$. Thus, the actual incidence of $\mathrm{PeV}-\mathrm{A}$ infection in clinical illnesses is unknown; and more importantly, delayed diagnosis and poor management in severe conditions remain unsolved.

PeV-A3 notably results in severe diseases of the central nervous system (CNS) and neonatal sepsis $(6,11,12)$, which is almost exclusively restricted to infants $<3$ months old (13). PeVA3 was reported as the leading cause of CNS infection in the United States (14). Neonates have increased risk of PeV-A3 infection due probably to reduced neutralization antibody protection (15). After PeV CNS infections, some of the neonates and young children exhibited neurological sequelae and neurodevelopmental delay (16). Different from PeV-A1, PeV-A3 lacks the Arginyl-Glycyl-Aspartic acid (RGD) motif in VP1 to bind integrin receptors to the cell membrane for entering cells $(17,18)$. Alternatively, PeV-A3 may use an unidentified receptor for infection and change its cellular tropism, resulting in enhanced ability to spread and replicate in the CNS $(19,20)$.

The mechanisms causing cell death can be classified as apoptosis, necrosis, cornification, autophagy, and pyroptosis $(21,22)$. Tollinterleukin receptor (TIR) domain-containing adaptor-inducing interferon- $\beta$ (TRIF), an adaptor for Toll-like receptor 3 (TLR3), was shown to induce apoptosis in Fas-associated Via Death Domain (FADD)-, caspase 3-, and caspase 8-dependent manner. Thus, TRIF links innate immunity and apoptosis pathways (23). In another cell death process, the mitochondria play an important role in controlling cell response upon virus infection (24). Autophagy features degradation of cellular components within the dying cell in autophagic vacuoles. The processes of autophagy include vacuolization, degradation of cytoplasmic contents, and slight chromatin condensation. Autophagy has been regarded as phylogenetically old process because of its involvement in the vertebrate development. Autophagy flux-involved cell death was revealed in virus-infected cells (25). Virus infection-mediated pyroptosis cell death was also reported (22). Pyroptosis is a kind of cell death accompanied with inflammation response. Several stimuli can trigger pyroptosis, such as infection, stroke, or cancer. Pyroptosis is found to be crucial for controlling microbial infections. Pathogens have developed mechanisms to inhibit pyroptosis, enhancing its persistence and ability to cause diseases. The competition between the host and the pathogen on the regulation of pyroptosis determines the life and death of the host (22).

The lack of a suitable infection model poses challenge to understanding the viral pathogenic and immunological mechanisms of PeV-A3 diseases (26). This study deciphered the mechanisms of in vitro and in vivo $\mathrm{PeV}$-A3-mediated neuropathogenesis, which would be helpful for developing strategies for $\mathrm{PeV}-\mathrm{A} 3$ prevention and treatment.

\section{MATERIALS AND METHODS}

\section{Cell Lines and Viruses}

Human glioblastoma (GBM) cells (DBTRG-05MG, GBM cells) (Bioresource Collection and Research Center, BCRC-60380, Hsinchu, Taiwan) were maintained in RPMI-1640 medium (Gibco, \#31800022, Waltham, MA, USA). Vero cells (American Type Culture Collection (ATCC), CCL-81, Manassas, VA, USA) and human neuroblastoma cells (IMR-32 cells, ATCC, CCL-127, Manassas, VA, USA) were cultured in MEM/EBSS medium (HyClone, \#SH30008.02, Logan, UT, USA). Cell culture mediums were supplemented with $10 \%$ fetal bovine serum (FBS) (Gibco, A4766801, Waltham, MA, USA) and penicillin-streptomycin (P/S) (Gibco, \#15140122, Waltham, MA, USA). PeV-A3 was from a virology group, Department of Microbiology, Kaohsiung Veterans General Hospital (27). PeVA3 was propagated in Vero cells. The full genome sequence of PeV-A3 (strain VGHKKS-2007 accession \#KM986843) has been characterized (28).

\section{Immunofluorescence Assay}

For cell staining, cells were plated at $1 \times 10^{4}$ cells/well in 96-well plates and incubated overnight. The cells were then infected with $\mathrm{PeV}-\mathrm{A} 3$ at multiplicity of infection $(\mathrm{MOI})=5$. After 8 - and $24-\mathrm{h}$ infection, the cells were fixed with 1:1 Methanol/Ethanol solution (Sigma-Aldrich, St. Louis, MO, USA) for $15 \mathrm{~min}$. Cells were incubated with blocking buffer $[10 \%$ skim milk in phosphatebuffered saline (PBS)] and incubated with anti-PeV VP0 polyclonal antibody at $4^{\circ} \mathrm{C}$ overnight (LTK BioLaboratories, Taoyuan, Taiwan) $(10,29)$. Then, the IRDye ${ }^{\circledR} 800 \mathrm{CW}$ goat antirabbit IgG secondary antibody was added into the cells (Li-COR, \#926-32211, Lincoln, NE, USA), followed by 2-h incubation. Images of immunofluorescence assay were captured, and the fluorescence intensity of PeV-A3-infected cells were quantified using Odyssey image system (Li-COR, Lincoln, NE, USA).

\section{RNA Extraction, Reverse Transcriptase PCR, and Quantitative Real-Time PCR}

Total RNA in cells or tissues were extracted first with $1 \mathrm{ml}$ of TRIzol $^{\text {TM }}$ reagent (Invitrogen, \#15596018, Waltham, MA, USA) and then with 1-bromo-3-chloropropane (BCP) (Sigma-Aldrich, B9673, St. Louis, MO, USA). The emulsion was centrifuged, and the aqueous phase was transferred to a fresh tube. The RNA was precipitated with $500 \mu \mathrm{l}$ of isopropanol (Sigma-Aldrich, \#278475, St. Louis, MO, USA) and pelleted by centrifugation at $12,000 \times \mathrm{rpm}$ at $4^{\circ} \mathrm{C}$ for $15 \mathrm{~min}$. RNA pellet was washed with $1 \mathrm{ml}$ of $75 \%$ ethanol and then centrifuged at $12,000 \times \mathrm{rpm}$ at $4^{\circ} \mathrm{C}$ for $10 \mathrm{~min}$. After removal of supernatant, RNA pellet was air-dried for $10 \mathrm{~min}$ in a laminar flow hood and resuspended in nuclease-free water.

The RNA concentration was measured using a spectrophotometer (Eppendorf, Hamburg, Germany). For reverse transcriptase, cDNA 
was synthesized using $50 \mathrm{mM}$ of random primer with $2 \mu \mathrm{g}$ of total RNA in a total reaction volume of $20 \mu \mathrm{l}$ using Superscript III reverse transcriptase method (Invitrogen, 18080085, Waltham, MA, USA). qPCR amplification involved 4 ng of cDNA in Fast SYBR ${ }^{\mathrm{TM}}$ Green Master Mix (Thermo Fisher, \#4385612, Waltham, MA, USA) with 3 $\mu \mathrm{M}$ of primers (Genomics, New Taipei City, Taiwan) (Table S1). qPCR was performed at $95^{\circ} \mathrm{C}$ for 3 min for 1 cycle and then $95^{\circ} \mathrm{C}$ for $20 \mathrm{~s}$ and $60^{\circ} \mathrm{C}$ for $30 \mathrm{~s}$ for 40 cycles. A final melting curve stage was performed from $60^{\circ} \mathrm{C}$ to $95^{\circ} \mathrm{C}$ using $\mathrm{ABI}$ StepOnePlus Real-Time PCR System (Life Technologies, Waltham, MA, USA).

\section{$\mathbf{R T}^{2}$ Profiler PCR Array}

The cDNA was synthesized from $2 \mu \mathrm{g}$ of total RNA with $50 \mathrm{mM}$ of random primer in a total reaction volume of $14 \mu \mathrm{l}$ using $\mathrm{RT}^{2}$ First Strand Kit (Qiagen, \#330401, Hilden, Germany). The cDNA quality control of genomic DNA contamination (GDC), first-strand synthesis (RTC), and real-time PCR efficiency (PPC) were confirmed according to the manufacturer's instruction. Finally, $25 \mu \mathrm{l}$ of PCR component mixture in each well was used for the analysis of human cell death pathway using $\mathrm{RT}^{2}$ Profiler PCR plate array (Qiagen, \#330231, Hilden, Germany) in ABI StepOnePlus Real-Time PCR System.

\section{Cell Viability Assay}

GBM cells $\left(1 \times 10^{4}\right.$ cells/well $)$ were grown in 96-well plates overnight and then infected with PeV-A3 at MOI $=0.1,1$, and 10. After infection for 6 and $24 \mathrm{~h}$, cells were incubated with $10 \mu \mathrm{l}$ of WST-1 reagent (Roche-Sigma-Aldrich, \#116448807001, St. Louis, MO, USA) for $2 \mathrm{~h}$. The absorbance at $450 \mathrm{~nm}$ was monitored, and the reference wavelength was set at $620 \mathrm{~nm}$ using a microplate spectrophotometer (Epoch, BioTek, Winooski, VT, USA).

\section{JC-10 Mitochondrial Membrane Potential Assay}

GBM and IMR-32 cells $\left(5 \times 10^{5}\right.$ cells/well $)$ were grown in six-well plates overnight and then infected with PeV-A3 at MOI $=1$ for $24 \mathrm{~h}$. After infection, cells were harvested for JC-10 analysis (Abcam, \#ab112133, Cambridge, England). Cells were suspended in $500 \mu \mathrm{l}$ of JC-10 solution and incubated at $37^{\circ} \mathrm{C}$ for $45 \mathrm{~min}$, protected from the light. Then, cells with fluorescence were analyzed using flow cytometry (BD FACSCalibur Franklin Lakes, NJ, USA). Fluorescence-activated cell sorting (FACS) analysis displayed cell subsets, which were estimated with respect to populations selected on the basis of membrane potential change. Apoptotic cells lost the mitochondria inner membrane potential, and the monomeric form of JC-10 was released into the cytoplasm. Cells displayed red fluorescence loss and turned green. The FL1 channel of FACS was used for detecting green fluorescent monomeric signal in apoptotic cells, while the FL2 channel was used for the detecting orange fluorescent aggregated signal in healthy cells.

\section{Western Blotting Analysis}

Cells and mouse brain tissue lysates were lysed in protein lysis buffer (2\% sodium dodecyl sulfate (SDS) and $50 \mathrm{mM}$ of Tris- $\mathrm{HCl}$, $\mathrm{pH}=7.5$ ) containing protease and phosphatase inhibitors (Thermo Fisher, \#78442, Waltham, MA, USA). The lysates were homogenously sonicated, separated in $10 \%$ or $12 \%$ SDS- polyacrylamide gel electrophoresis (PAGE), and finally transferred to polyvinylidene difluoride (PVDF) membranes (Millipore, IPVH00010, Burlington, MA, USA). PVDF membranes were treated with $10 \%$ milk blocking buffer and incubated with primary antibody in 1:2,000 dilution in 5\% milk/ TBST at $4^{\circ} \mathrm{C}$ overnight, Antibodies used included anti-PeV VP0 (10), anti-caspase 3 (Cell Signaling, \#9662, Danvers, MA, USA), anti-caspase 7 (GeneTex, GTX123679, Hsinchu City, Taiwan), antiPARP (Cell Signaling, \#9532, Danvers, MA, USA), anti-caspase 8 (Cell Signaling, \#9746, Danvers, MA, USA), anti-caspase 9 (Cell Signaling, \#9508, Danvers, MA, USA), anti-FASLG (GeneTex, GTX31191, Irvine, CA, USA), anti-CD40 (GeneTex, GTX101447, Irvine, CA, USA), anti-LC3 A/B (Cell Signaling, \#4108, Danvers, MA, USA), anti-p62 (Cell Signaling, \#16177, Danvers, MA, USA), anti-beclin 1 (Cell Signaling, \#3495, Danvers, MA, USA), antiphospho-NF-kB p65 (Ser536) (Cell Signaling, \#3033, Danvers, MA, USA), anti-NLRP3 (Cell Signaling, \#13158, Danvers, MA, USA), anti-IL1 $\beta$ (Cell Signaling, \#12242, Danvers, MA, USA), anti-RIPK1 (R\&D, MAB3585, Minneapolis, MN, USA), anti-RIPK3 (R\&D, MAB7604, Minneapolis, MN, USA), anti-GSDMD (GeneTex, GTX135366, Hsinchu City, Taiwan), anti- $\beta$-actin (ProteinTech, \#66009-1-Ig, Rosemont, IL, USA), and anti-GAPDH (ProteinTech, \#60004-1-Ig, Rosemont, IL, USA). Secondary antibodies conjugated with horseradish peroxidase (HRP)-anti mouse (LEADGENE, 20112, Tainan, Taiwan) and HRP-anti rabbit (LEADGENE, \#20202, Tainan, Taiwan) were incubated at room temperature $1 \mathrm{~h}$. The images were acquired from biospectrum imaging system (UVP Analytik Jena, Jena, Germany) by using WesternBright ECL kit (Advansta, K-12045D20, Menlo Park, CA, USA).

\section{Virus Infection and Disease Symptoms Observed in Neonatal Mice}

C57BL/6 mice were purchased from the National Laboratory Animal Center (NARLabs, Taipei, Taiwan). This study was approved by the Institutional Animal Care and Use Committee or Panel (IACUC) in Kaohsiung Veterans General Hospital, Taiwan (IACUC Approval No. VGHKS-2018-2021-A016). According to the reported method of intracranial injection of virus (30), 3-dayold C57BL/6 neonatal mice were intracranially inoculated with PeV-A3 $\left(5 \times 10^{5} \mathrm{pfu} /\right.$ mouse $)$ into the cerebral lateral ventricles using Hamilton 1700 Series Syringes (Hamilton, 80000, Reno, NV, USA). PBS inoculation on mice was the control. Survival rate, clinical scores, and body weight were then monitored daily after inoculation. Clinical scores $0-5$ indicated the severity level of disease symptoms: 0 , healthy; 1 , reduced mobility; 2 , reduced body weight; 3 , forelimb or hindlimb weakness; 4 , forelimb or hindlimb paralysis; and 5 , death.

\section{Immunohistochemistry}

Paraffin-embedded brain tissues from PeV-A3 mice and PBS mice were cut and mounted on coated slides. The sections were deparaffinized in xylene and rehydrated through graded alcohol solutions, and antigen retrieval in sodium citrate buffer at $100^{\circ} \mathrm{C}$ for $20 \mathrm{~min}$ was performed. The immunohistochemistry (IHC) procedures of Novolink Polymer Detection Systems (Leia \#RE7150-K, Wetzlar, Germany) were modified. Brain sections 
were incubated with Protein Block buffer for blocking 15 min and then incubated overnight at $4^{\circ} \mathrm{C}$ with rabbit polyclonal antibody anti-PeV-VP0 and rabbit IgG isotype control (Thermo Fisher, \#026102, Waltham, MA, USA). After being rinsed with PBS (Biological Industries \#11-223-1M Cromwell, CT, USA), the slides were incubated with secondary antibody goat anti-rabbit IgG Alexa Flour 488 (1:500 dilution, Thermo Fisher, \#A32731, Waltham, MA, USA) for $1 \mathrm{~h}$ at room temperature. The slides were mounted after DAPI staining (1:5,000 dilution, Thermo Fisher \#62248, Waltham, MA, USA) for $30 \mathrm{~min}$. The hippocampus and cortex regions were observed under an inverted fluorescence microscope (Olympus, Tokyo, Japan).

\section{Statistical Analysis}

Statistical analysis was performed using Prism 9 (GraphPad, San Diego, CA, USA). Student's t-test or Mann-Whitney U test were used for quantitative parameters. Survival rates were analyzed using Kaplan-Meier curve. Results were expressed as mean \pm SD. $p$-Value of $<0.05$ was considered to be significant.

\section{RESULTS}

\section{Parechovirus Type 3 Replication in Human Glioblastoma and Neuroblastoma Cells}

GBM cells and neuroblastoma cells were used in research on neurotropic virus infections such as ZIKA virus and enterovirus
71 (31-34). Therefore, this study used human GBM cells (DBTRG-05MG) and human neuroblastoma cells (IMR-32) to decipher the neuropathic effects of PeV-A3. These two cell lines were infected with $\mathrm{PeV}-\mathrm{A} 3$ at $\mathrm{MOI}=5$ for 8 and $24 \mathrm{~h}$, followed by immunofluorescence analysis conducted with anti-PeV VP0 antibody. Green fluorescence indicated VP0 expression in PeVA3-infected cells (Figures 1A, B, top panels). The fluorescence level was further quantified. Comparison with mock controls and results at $8 \mathrm{~h}$ post infection (h.p.i) revealed an increased VP0 expression level detected at 24 h.p.i. (Figures 1A, B, bottom panels). The viral genome in GBM cells infected with PeV-A3 at MOI $=0.1,1,5$, and 10 was measured. A gradual viral loaddependent increase in PeV-A3 VP1 mRNA level was observed (Figure 1C). Taken together, these results showed susceptibility of GBM and neuroblastoma cells to PeV-A3 infection.

\section{Induction of Type I and Type III IFN by Parechovirus Type 3 and Inhibition of Parechovirus Type 3 Replication by IFN Treatment}

During viral infection, cellular type I and type III IFN antiviral responses are evoked to restrict virus replication (35). In the CNS, type I IFN protects neurons from prion infection (36). To clarify the $\mathrm{PeV}$-A3-induced antiviral response in GBM, we measured the IFN and associated antiviral protein expression after infection for 24 and $48 \mathrm{~h}$. RT-qPCR results showed significant induction of the determined genes, which were IFN-
A
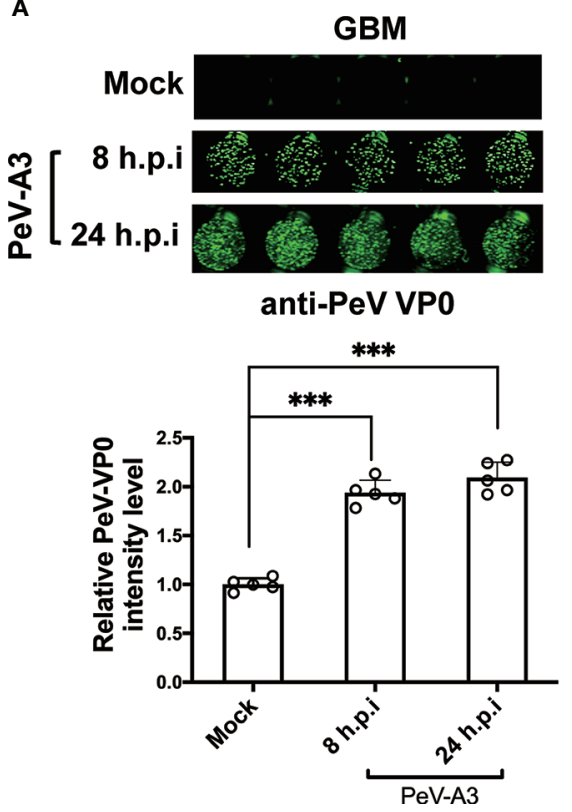

B

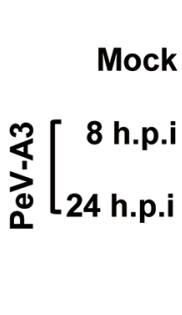

IMR-32

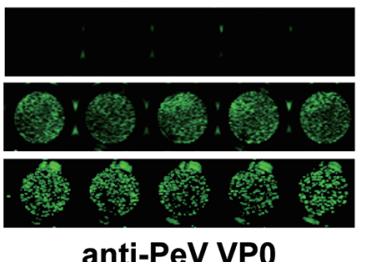

anti-PeV VPO

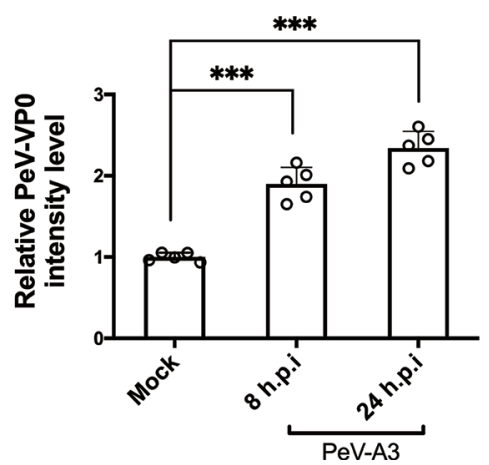

C

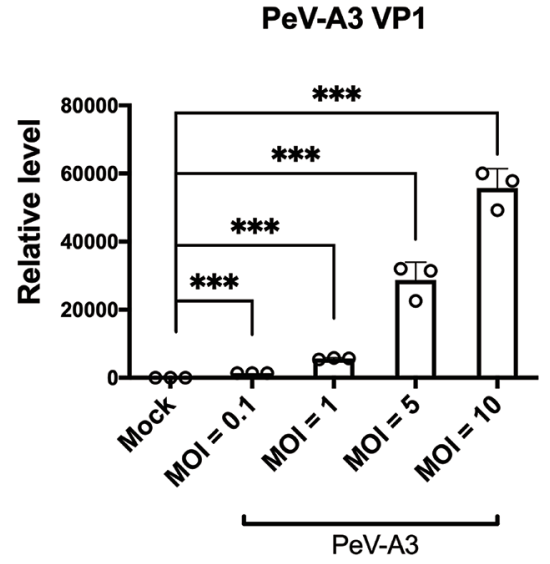

FIGURE 1 | Replication of PeV-A3 infection in GBM and IMR-32 cells. (A) GBM and (B) IMR-32 cells were infected with PeV-A3 at MOI = 5 for 8 and 24 h. Cells were then stained with anti-PeV APO antibody followed by IRDye ${ }^{\circledR} 800 \mathrm{CW}$ goat anti-rabbit IgG secondary antibody. The cell images of immunofluorescent assay were captured (top panels) using Odyssey image system. Fluorescence intensities of PeV-A3-infected cells were quantified (bottom panels). Data are mean \pm SD of five independent experiments. Student's t-test, ${ }^{* * *} p<0.001$. (C) RT-qPCR of PeV-A3 VP1 expression in GBM cells infected with PeV-A3 at MOI = 0.1, 1, 5, and 10 for $24 \mathrm{~h}$. Data are mean \pm SD. Student's t-test, ${ }^{\star \star \star} p<0.001$ compared with mock controls. PeV-A3, parechovirus type 3; GBM, glioblastoma; MOI, multiplicity of infection; VP1, viral protein 1. 
$\beta$, type III IFN (IFN $\lambda$-1, IFN $\lambda$-2/3), TANK-binding kinase 1 (TBK1), interferon regulatory factor 3 (IRF3), melanoma differentiation-associated protein 5 (MDA5), C-X-C motif chemokine ligand 10 (CXCL10), retinoic acid-inducible gene I (RIG-I), and mitochondrial antiviral-signaling protein (MAVS) transcripts (Figure 2A). These findings suggested that PeV-A3 activated cellular antiviral responses in GBM cells.

We further investigated type I IFN activity against PeV-A3 in GBM. Cells were infected with PeV-A3 at MOI $=1$ for $48 \mathrm{~h}$ after being pretreated or posttreated with type I IFN $100 \mathrm{IU} / \mathrm{ml}$ for 24 h. RT-qPCR results showed reduction of viral replication along with induction of type I and type III IFN and ISGs (MDA-5 and 2'-5'-Oligoadenylate Synthetase 2, OAS2) (Figure 2B). PeV-A3activated antiviral responses and exogenous type I IFN treatment-suppressed PeV-A3 suggest a typical virus-host interaction in GBM cells.

\section{Parechovirus Type 3 Caused Cytopathic Effect in Neuronal Cells}

Although type I IFN response was elicited by PeV-A3 in GBM cells, the host antiviral activity failed to efficiently restrict this virus, with both GBM and IMR-32 cells showing cytopathic effect (CPE) morphology upon PeV-A3 infection at MOI $=1$ for $24 \mathrm{~h}$ (Figure 3A). The WST-1 assay of GBM cells proliferation was impaired by $\mathrm{PeV}-\mathrm{A} 3$, revealing a decreased cell growth in a viral load-dependent manner (Figure 3B). This study further investigated whether PeV-A3 infection caused mitochondrial membrane potential change using cationic, lipophilic JC-10 dye staining in GBM and IMR-32 cells. Compared with $12.6 \%$ and $6.38 \%$ of mock-infected GBM and IMR-32 cells, respectively showing JC- 10 background signaling, $36 \%$ and $24.3 \%$ of PeVA3-infected GBM and IMR-32 cells respectively exhibited mitochondrial membrane potential loss, becoming apoptotic cells (Figure 3C). Collectively, these findings revealed a pathogenic effect of $\mathrm{PeV}-\mathrm{A} 3$ in neuronal cell types.

To understand the expression pattern of cell death-related genes in PeV-A3-infected GBM cells, the human $\mathrm{RT}^{2}$ profiler PCR array was conducted (Table S2). Results showed that PeVA3-infected GBM cells expressed death protein genes at least twofold upregulated over mock controls including myelinassociated glycoprotein (MAG), Fas ligand (FASLG), BCL2related protein A1 (BCL2A1), ATPase $\mathrm{H}+$ Transporting V1 Subunit G2 (ATP6V1G2), insulin-like growth factor 1 (IGF1), Forkhead box I1 (FOXl1), and tumor necrosis factor receptor superfamily, member 11b (TNFSR11B) (Figures S1A, B). The expression level of these genes was further confirmed using RTqPCR analysis, which showed a significant induction, compared with mock controls (Figure 3D and Table S3). Hence, results obtained evidenced that PeV-A3 infection triggered cell deathassociated gene transcript in GBM cells.

\section{Parechovirus Type 3 Activated Cell Death Signaling Pathways in Glioblastoma Cells}

Programmed cell death is an important machinery in host's defense to limit the replication of invading intracellular pathogens. Types of viral-mediated cell death included apoptosis, programmed necrosis, autophagy, and pyroptosis; the events promote the formation of effective long-term host immune inflammation and innate responses $(23,37)$. After detection of PeV-A3-mediated cell death, death signaling was analyzed to understand the cellular activity in response to $\mathrm{PeV}$ A3 infection. Immunoblotting of signaling proteins was conducted in GBM cells infected with PeV-A3 for 6, 24, and $48 \mathrm{~h}$. The protein level was also quantified and statistically analyzed. The time dependently increased PeV-A3 VP0 protein level revealed the spread of viral infection status in GBM cells. We detected significant increase in signaling protein level underlying apoptosis and pro-apoptosis pathways, such as activated caspase-3, caspase-7, PARP, caspases 8, caspase 9, FASLG, and CD40, after PeV-A3 infection in a timedependent manner (Figure 4A left panel and Figure 4B).

Autophagy is a process that consigns cytoplasmic components to lysosomes for degradation. Autophagy is usually associated with cell death. Autophagy-associated cell death depends largely on the physical conditions $(37,38)$. Autophagy-induced NFKB activity was also reported, which could be targeted by viral infection $(39,40)$. This study found significant accumulation of autophagic factors LC3 and p62 and a slight increase in the beclin-1 level of GBM cells during PeV-A3 infection periods. The induced phosphorylated NF- $\mathrm{KB}$ p65 Ser536 activity was also detected. The above results suggested that PeV-A3 infection-associated autophagy influx is possibly involved in $\mathrm{PeV}$-A3-triggered cell death (Figure 4A, right panel, and Figure 4B). Since PeV-A3-caused neuronal cell death was revealed (Figure 3C), we also analyzed the apoptosis and proapoptosis and autophagy signaling responses in IMR-32 cells with PeV-A3 infection. Compared with that of mock controls, the increased protein level of activated caspase 3, CD40, FASLG, LC3, and p62 was detected (Figure S2).

Pyroptosis is a type of cell death accompanied with inflammation and is essential for limiting pathogen infections. Infections stimulate pyroptosis activation and formation of NLR family pyrin domain containing 3 (NLRP-3) inflammasome, resulting in processing and activation of caspase 1 for expression of inflammatory cytokines interleukin $1 \beta$ (IL-1 $\beta$ ) and IL-18 $(41,42)$. In the signal pathways of NLRP3-mediated pyroptosis, IL-1 $\beta$ and receptor-interacting protein (RIP) family of serine-threonine kinases, RIPK1 and RIPK3, Gasdermin-D (GSDMD) were detected in PeV-A3-infected GBM cells (Figure 4A, right panel, and Figure 4B). This study detected activation of death signaling of apoptosis, autophagy, and pyroptosis as early as 6 h.p.i. in GBM cells, suggesting a fast pathogenic response promoted upon $\mathrm{PeV}-\mathrm{A} 3$ replication. Together, these results suggested that $\mathrm{PeV}-\mathrm{A} 3$ induced multiple cell death signaling pathways.

\section{Parechovirus Type 3 Induced Inflammatory Cytokines}

In view of PeV-A3 infection-triggered signaling activation of autophagy and pyroptosis, this study then accessed autophagyand pyroptosis-mediated inflammatory cytokine expression responses in GBM and IMR-32 cells. These cells were infected 
A
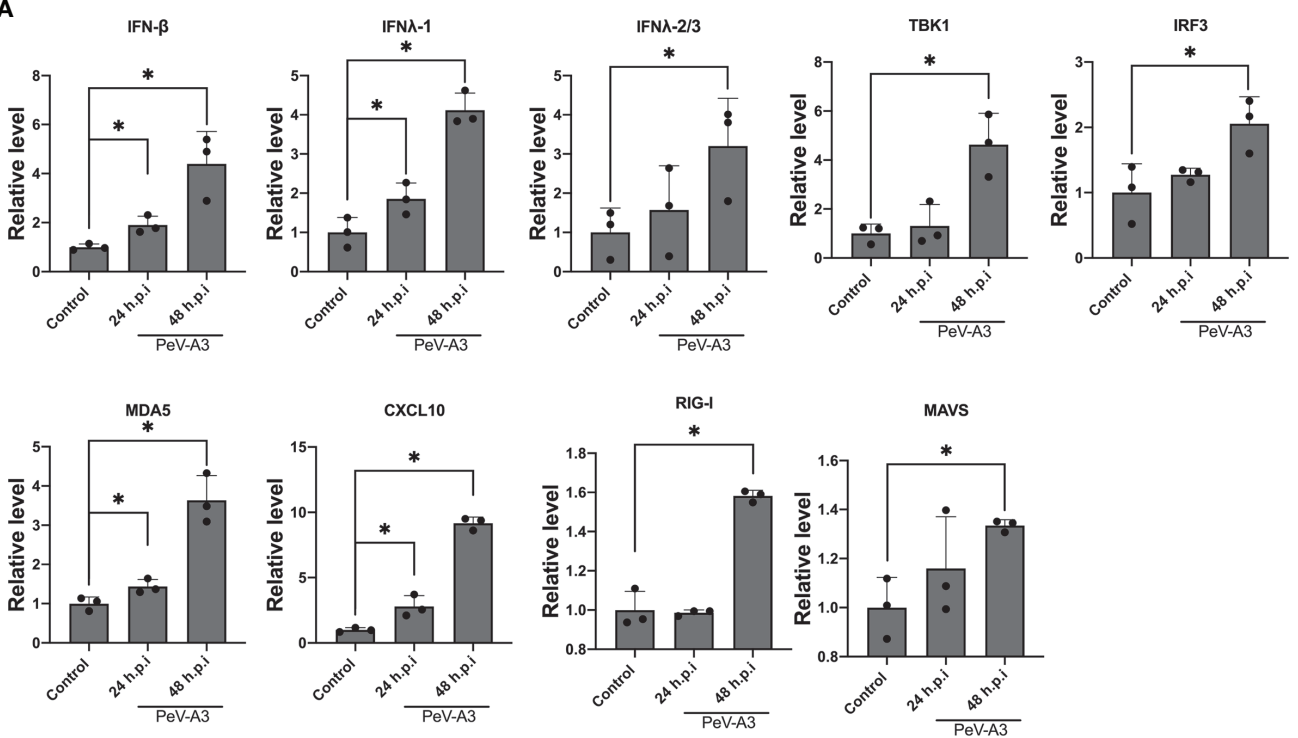

B
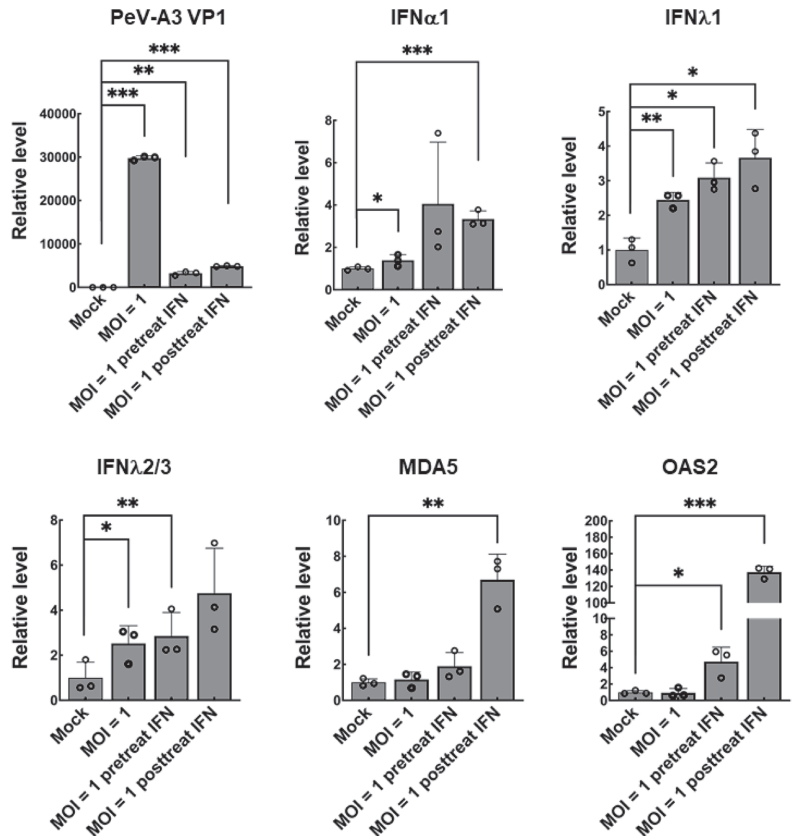

FIGURE 2 | PeV-A3 infection activated cellular antiviral innate immunity. (A) GBM cells were infected with PeV-A3 at MOI = 1 for 24 and 48 h. mRNA levels of antiviral genes IFN $\beta$, IFN $\lambda 1$, IFN 2 2/3, TBK1, IRF3, MDA5, CXCL10, RIG-I, and MAVS were confirmed using RT-qPCR. The level of transcripts was normalized by GAPDH. Data are mean \pm SD of three independent experimental samples. Student's t-test, * $P<0.05$ compared with mock controls. (B) Efficacy of type I IFN against PeV-A3. IFN- $\alpha 2$ measuring $100 \mathrm{lU} / \mathrm{ml}$ was pretreated or posttreated in GBM cells for $24 \mathrm{~h}$. GBM cells were infected with PeV-A3 at MOI = 1 for $24 \mathrm{~h}$. Expression of mRNA of IFN $\alpha 1$, IFN $\lambda 1$, IFN $\lambda 2 / 3$, MDA5, and OAS2 was measured using RT-qPCR and normalized to GAPDH. Data are mean \pm SD of three independent samples. Student's t-test, ${ }^{\star} p<0.05 ;{ }^{\star \star} p<0.01,{ }^{\star \star \star} p<0.001$ compared with mock controls. PeV-A3, parechovirus type 3; GBM, glioblastoma; MOI, multiplicity of infection.

with PeV-A3 for 6,24 , and $48 \mathrm{~h}$, followed by the induction of TNF- $\alpha$, IL-6, IL- $1 \beta$, and IL-18 measured using RT-qPCR. Results showed similar transcript patterns in GBM (Figure 5A) and IMR-32 cells (Figure 5B), where inflammatory cytokines, TNF- $\alpha$, IL-6, IL-1 $\beta$, and IL-18 transcripts, were significantly induced at 6 h.p.i. and then declined at 24 and 48 h.p.i. These data suggested that, consistent with early activation of death signaling by $\mathrm{PeV}-\mathrm{A} 3$ shown in Figure 6, an early response of inflammatory transcript in GBM cells was also detected. The reduction of these 

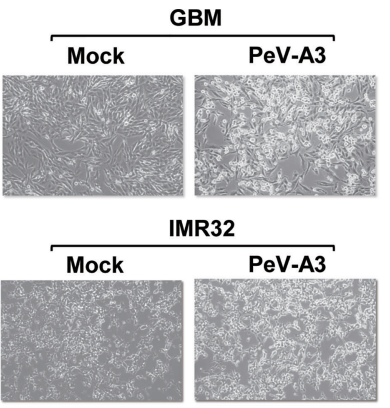

C
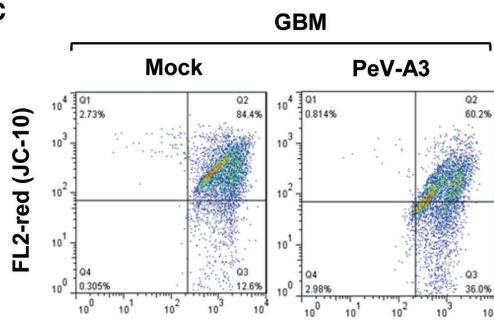

FL1-green (FITC)

B
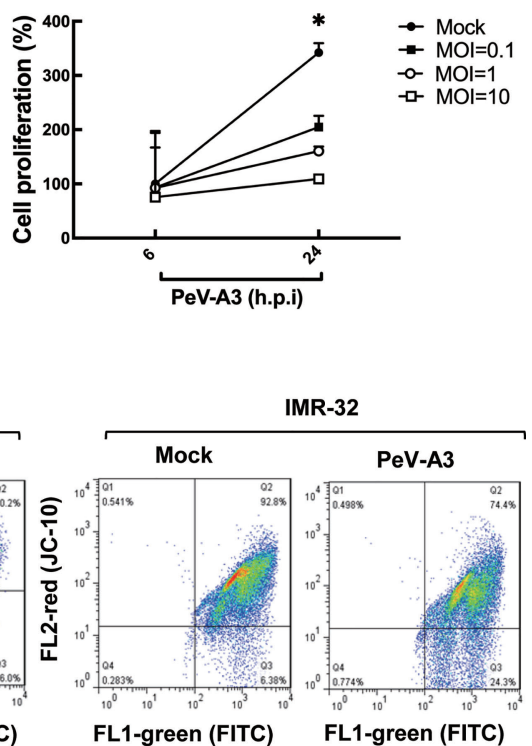

D
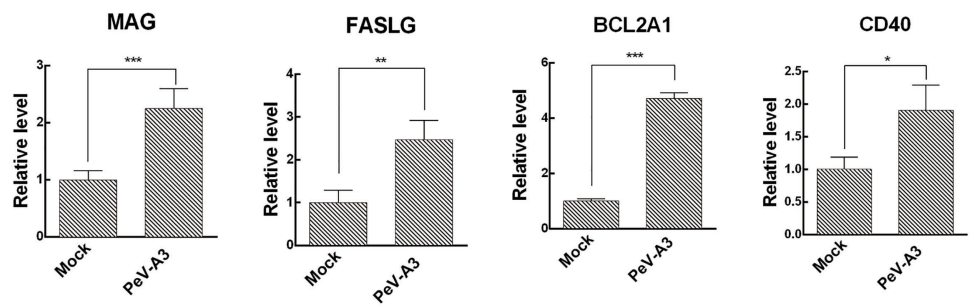

ATP6V1G2

IGF1
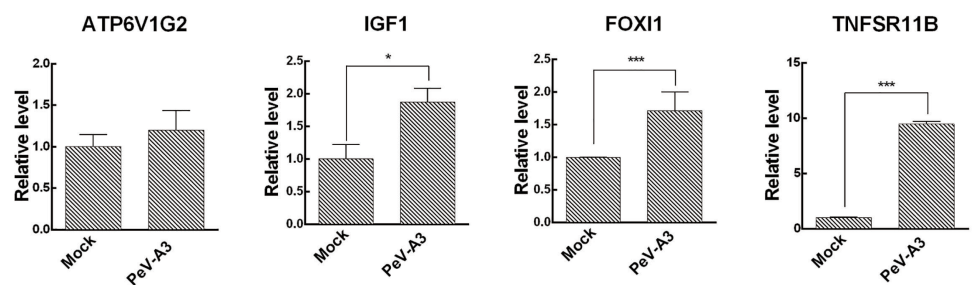

FIGURE 3 | PeV-A3 induced cell death. (A) CPE observation of GBM and IMR-32 cells infected with PeV-A3 at MOI = 1 for 24 h. (B) WST-1 assay was conducted in GBM cells infected with PeV-A3 at MOI $=0.1,1$, and 10 for 6 and $24 \mathrm{~h}$. Cell viability was detected in a microplate ELISA reader at absorbance OD $450 \mathrm{~nm}$ and reference wavelength OD $620 \mathrm{~nm}$. (C) Flow cytometry analysis of JC-10 mitochondrial membrane potential detection in PeV-A3-infected GBM and IMR-32 cells. Cells located in Q2 area are healthy. Cells located in Q3 are damaged, showing loss of mitochondrial inner membrane potential. (D) RT-qPCR analysis of genes identified using $\mathrm{RT}^{2}$ array. RT-qPCR was conducted in PeV-A3-infected GBM cells and mock controls. Data are mean $\pm \mathrm{SD}$ of three independent experiments. Student's t-test, ${ }^{\star} p<0.05 ;{ }^{\star \star} p<0.01 ;{ }^{\star \star \star} p<0.005$ compared with mock controls. PeV-A3, parechovirus type 3; CPE, cytopathic effect; GBM, glioblastoma; MOI, multiplicity of infection; OD, optical density.

inflammatory genes might be due to impaired cells' viability and low activity of host gene transcription. Collectively, the above findings revealed the neuropathogenic mechanism of PeV-A3 in vitro.

\section{Parechovirus Type 3 Caused Neuropathic Symptoms in Neonatal Mice}

The above findings evidenced that PeV-A3 infection inhibited cell growth and activated cell death pathways including apoptosis, autophagy, and pyroptosis in vitro. To investigate the PeV-A3-induced neuropathic disease in vivo, we established a PeV-A3 infection animal model by using 3-day-old C57BL/6 mice. Neonate mice were intracranially inoculated with $\mathrm{PeV}-\mathrm{A} 3$ at $5 \times 10^{5} \mathrm{pfu} /$ mouse, while littermates that received PBS injection served as mock controls. After inoculation, the survival rate was monitored from day 0 to day 11 . Results showed approximately $20 \%$ mortality in PeV-A3-infected mice (Figure 6A). 
A

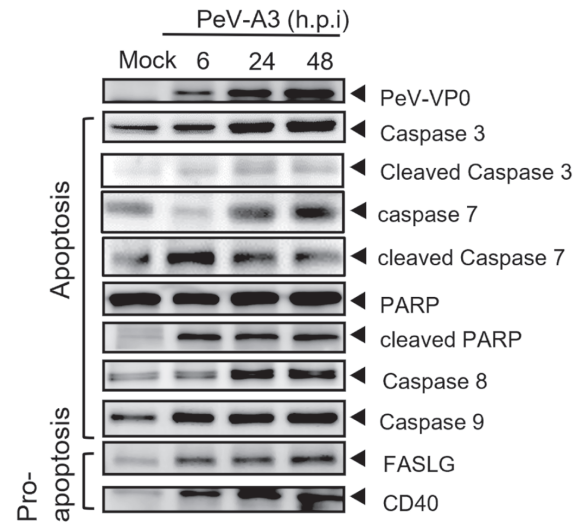

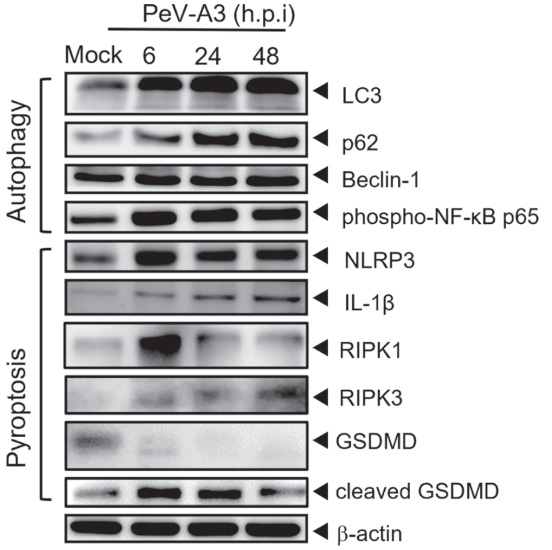

B
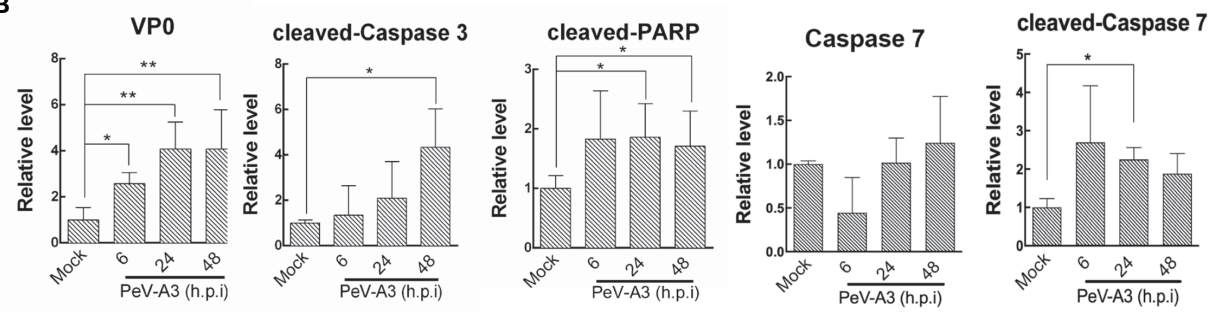

Caspase 8
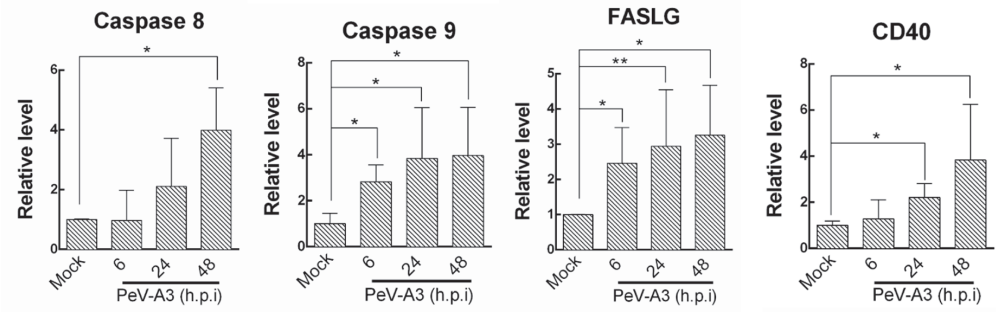

Beclin 1
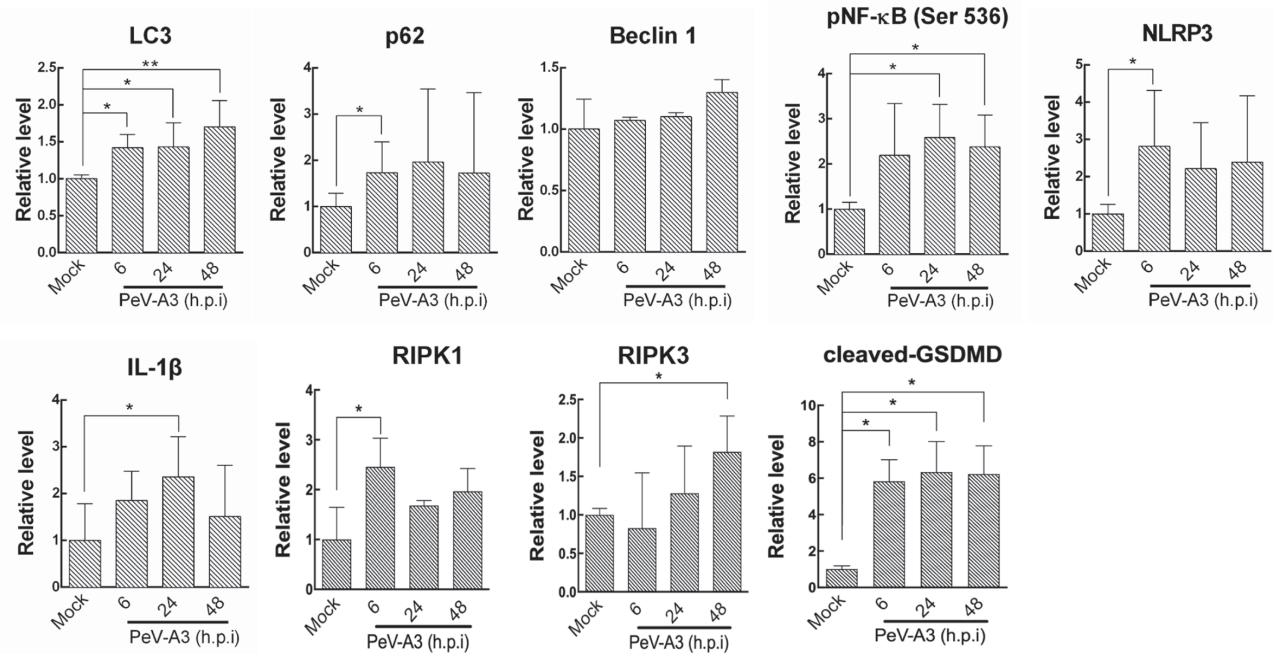

FIGURE 4 | Cell death signaling analysis in PeV-A3-infected GBM cells. (A) GBM cells were infected with PeV-A3 at MOI = 1 for 6, 24, and 48 h. Cell extracts were employed to analyze cell death signaling pathways by Western blotting using anti-PeV VPO, anti-caspase 3, anti-PARP, anti-caspase 8, anti-caspase 9, anti-FASLG, anti-CD40, anti-LC3, anti-p62, anti-beclin 1, anti-phospho-NF-kB p65 (Ser536), anti-NLRP3, anti-IL1 $\beta$, anti-RIPK1, anti-RIPK3, anti-GSDMD, and anti- $\beta$-actin .

(B) Quantified expression of different proteins was normalized to $\beta$-actin. Data are mean $\pm \mathrm{SD}$ of three independent experiments. Student's t-test, ${ }^{*} p<0.05$; ${ }^{* *} p<$

0.01 compared with mock controls. PeV-A3, parechovirus type 3; GBM, glioblastoma; MOI, multiplicity of infection. 

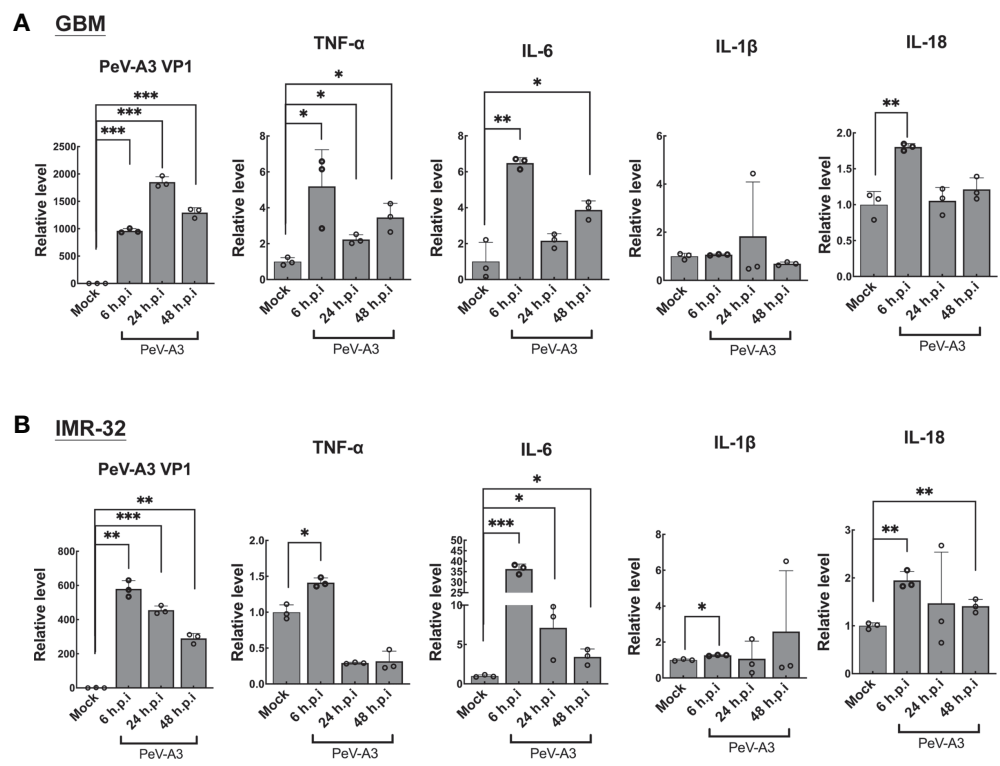

FIGURE 5 | PeV-A3 induced expression of pyroptosis-associated inflammatory cytokines. (A) GBM cells and (B) IMR-32 cells were infected with PeV-A3 at MOI = 1 for 6, 24, and $48 \mathrm{~h}$. TNF- $\alpha$, IL-6, IL-1 $\beta$, and IL-18 were analyzed using RT-qPCR. Data are mean \pm SD of three independent experiments. Student's t-test ${ }^{*} p<0.05$; ${ }^{* *} P<0.01 ;{ }^{* *} p<0.001$ compared with mock controls. PeV-A3, parechovirus type 3; GBM, glioblastoma; MOI, multiplicity of infection.

After infection for 11 days, the mice were sacrificed, and total RNA was extracted from the brain tissues to analyze the PeV-A3 VP1 mRNA expression. RT-qPCR results showed significant expression of PeV-A3 RNA in mouse brain as compared with $\mathrm{PBS}$ control (Figure 6B). The PeV-VP0 protein expression in each mouse brain was also detected by immunoblotting, and the protein level was quantified (Figure 6C). The PeV-A3 viral RNA and protein expression indicated replication of $\mathrm{PeV}-\mathrm{A} 3$ in the neonatal mouse brain.

According to the severity of physical condition of the mice (health, reduced mobility, body weight loss, limb weakness, paralysis, and death; Figure 6D, top panel), clinical symptoms observed from days 0 to 11 post injection were scored. Days 2, 6, and 11 showed progression of disease with increasing clinical scores in PeV-A3-infected mice (Figure 6D, bottom panel). The images showed mice with limb paralysis or moribund (Figure 6E). These results suggested that $\mathrm{PeV}-\mathrm{A} 3$ induced strong neurovirulence in $\mathrm{C} 57 \mathrm{BL} / 6$ mice. Changes in daily body weight in surviving PeV-A3-infected mice were measured. The findings showed lower average body weight in $\mathrm{PeV}$-A3-infected C57BL/6 neonatal mice at days 2, 6, and 11 after inoculation as compared with PBS control mice (Figure 6F). This infection animal model demonstrated susceptibility of neonatal C57BL/6 mice to $\mathrm{PeV}-\mathrm{A} 3$ infection, which caused neuropathic symptoms and decreased survival rate.

\section{Parechovirus Type 3 Infection in the Hippocampus and Cortex of Brain}

$\mathrm{PeV}-\mathrm{A} 3 \mathrm{RNA}$ and protein were detected in the brain extracts of infected mice. We further conducted IHC analysis to understand whether the hippocampus and cortex of brain regions were infected by $\mathrm{PeV}-\mathrm{A} 3$. The result showed that the PeV-VP0 expression was detected in the hippocampus and cortex in the $\mathrm{PeV}$-A3-infected mice, but not in the PBS control mice (Figures 7A, B). Quantification data showed a significant high level of PeV-VP0 expression in the hippocampus and cortex; compared with PBS control, nearly 40 -fold and 70 -fold protein level increases were detected in the hippocampus and cortex sections, respectively (Figures 7C, D). Taken together, these results suggest that $\mathrm{PeV}-\mathrm{A} 3$ directly infected hippocampus and cortex regions of the neonatal mouse brain.

\section{Parechovirus Type 3 Induced Inflammatory Cytokines and Death Signaling in Mouse Brain Tissues}

$\mathrm{PeV}-\mathrm{A} 3$ caused neurological symptoms in neonatal mice. Mouse brain tissues were examined to understand whether the present in vitro findings of $\mathrm{PeV}$-A3-triggered inflammation and whether cell death signaling activation also occurred in the infected mice. RT-qPCR results showed a higher transcript level of inflammatory cytokines (Tnfa, Il-6, Il-8, and Il-1b) and interferon signature [Ifna, Ifnb, Ifng, interferon regulatory factor 3 (Irf3), Irf7, Viprin, and Toll-like receptor 3 (Tlr3)] in $\mathrm{PeV}-\mathrm{A} 3$-infected brain tissues compared with PBS controls (Figure 8). Furthermore, the protein extract from each mouse brain tissue was employed to analyze death signaling; the quantified immunoblots demonstrated that brain tissues of PeV-A3-infected mice expressed a higher protein level of activated cleaved-caspase 3, cleaved-PARP, LC3, phospho-NF$\kappa \mathrm{B}$ p65, IL-1 $\beta$ cytokine, and RIPK1 than did PBS controls 
C57BL/6 neonatal mice

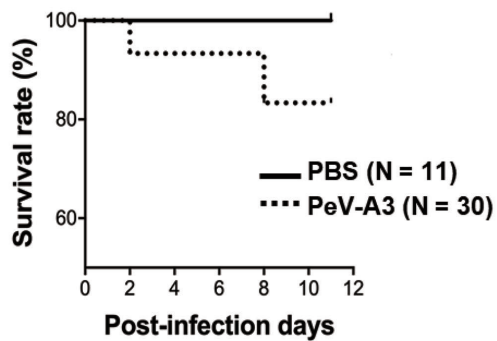

C

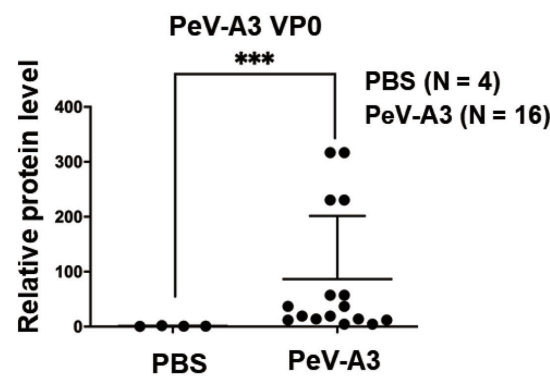

E

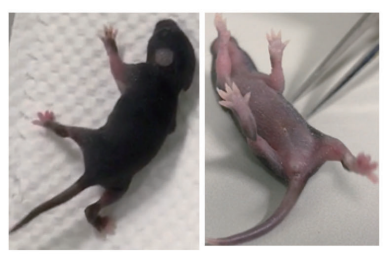

B

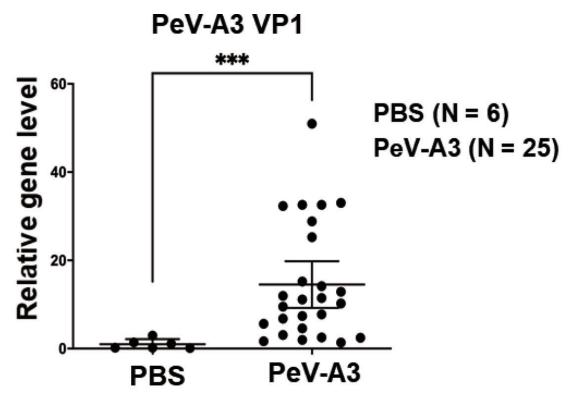

D
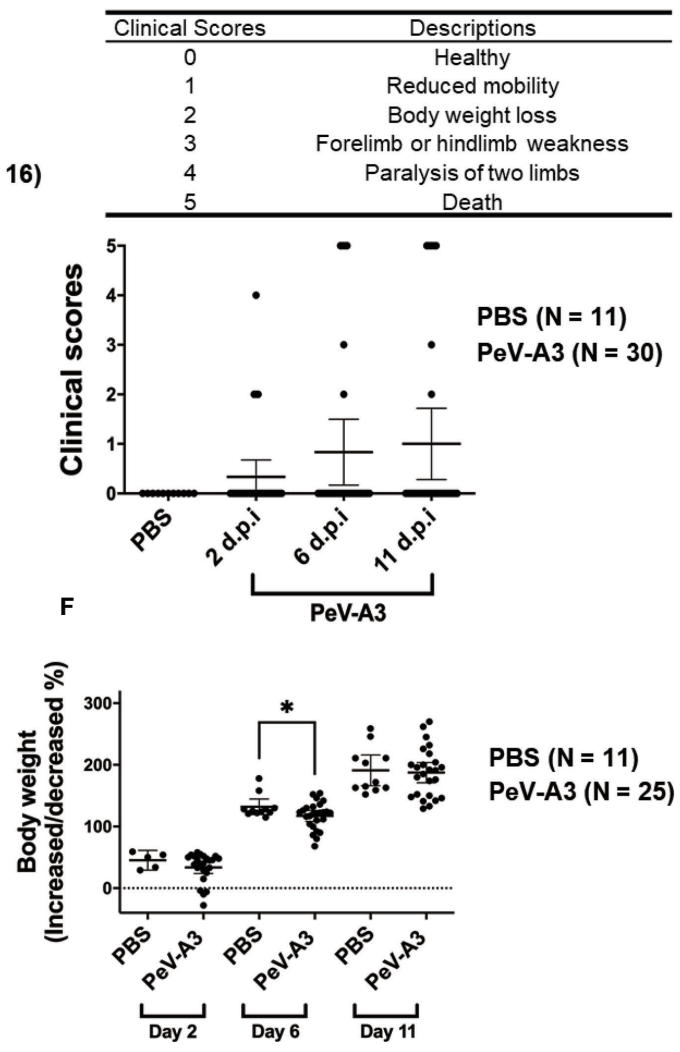

FIGURE 6 | PeV-A3 caused neuronopathic effects in C57BL/6 neonatal mice. (A) Three-day-old C57BL/6 mice were intracranially inoculated with PeV-A3 $\left(5 \times 10^{5}\right.$ pfu/mouse) or PBS as mock controls. The survival rate was monitored from days 0 to 11 after inoculation (PBS N=11, PeV-A3 N=30). Mann-Whitney $U$ test, ${ }^{\star \star \star *} p$ $<0.001$ compared with PBS controls. (B) Eleven days after inoculation, the mice were sacrificed, and total RNA was isolated from brain tissues for PeV-A3 VP1 mRNA detection. Data are mean $\pm \mathrm{SD}$, PBS group, $\mathrm{N}=6$; PeV-A3 group, $\mathrm{N}=25$. Independent two-sample t-test, $p<0.001$ compared with PBS controls. (C) Mouse brain tissue protein lysates were subjected to immunoblotting with anti-PeV-VPO and anti-GAPDH; the relative expression of PeV-A3 VPO protein was normalized using GAPDH. PBS controls, $N=4$, PeV-A3 $N=16$. Independent two-sample t-test, ${ }^{* \star *} p<0.001$ compared with PBS mock control. (D) Description of clinical symptoms corresponded with clinical scores: 0 , healthy; 1 , reduced mobility; 2 , reduced body weight; 3 , forelimb or hindlimb weakness; 4 , forelimb or hindlimb paralysis; and 5, death. Clinical scores were monitored daily. Clinical score in mice after inoculation at days 2, 6, and 11 were shown. Data are mean \pm SD. PBS group, $\mathrm{N}=11$, PeV-A3 group, $\mathrm{N}=30$. Independent two-sample t-test. (E) Photo images showed PeV-A3 infection caused paralysis in two limbs at day 2 after inoculation in C57BL/6 mice. (F) Changes in body weight were measured daily. Changes in mice weight after inoculation at days 2, 6, and 11 are shown. Data are mean $\pm \mathrm{SD}$, PBS control group, $\mathrm{N}=11$; PeV-A3, $N=25$. Independent two-sample t-test, ${ }^{*} p<0.05$ compared with PBS controls. PeV-A3, parechovirus type 3 ; PBS, phosphate-buffered saline; VP1, viral protein 1.

(Figures 9A, B). These results suggested that PeV-A3 infection induced inflammatory cytokine expression and activated apoptosis, autophagy, and pyroptosis signaling pathways in neonatal mice, which might be associated with the neurovirulence of $\mathrm{PeV}-\mathrm{A} 3$.

\section{DISCUSSION}

Viral meningoencephalitis is a life-threatening illness in humans that can be caused by different viruses. PeV-A3 has been known as a severe viral infection in neonates and young infants, causing 


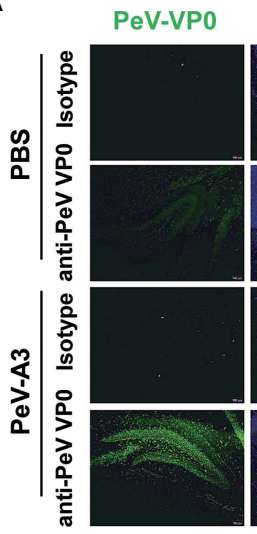

B
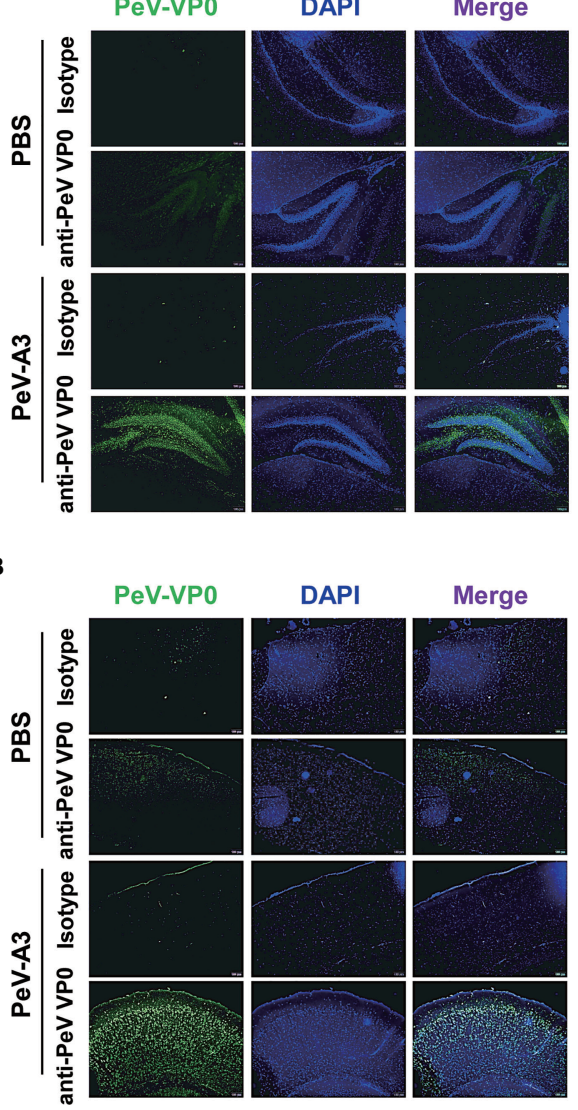

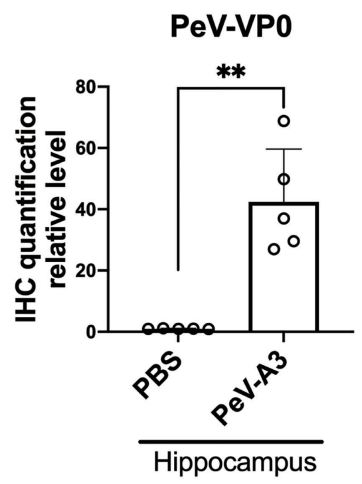

D

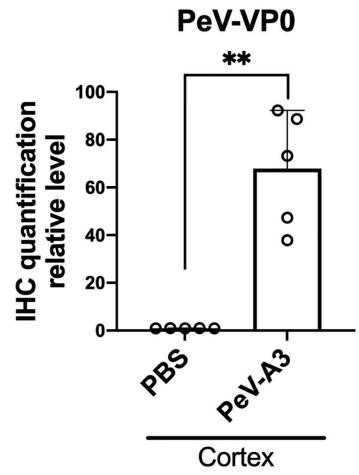

FIGURE 7 | Fluorescence immunohistochemistry assay (IHC) of PeV-A3 infection in neonatal mouse brain. (A, B) Immunohistochemically staining for PeV-VPO in the hippocampus and cortex section (PBS control, $N=5$; PeV-A3, $N=5$ ). Scale bar $=100 \mu \mathrm{m}$. (C, D) Quantified PeV VPO protein level of the $\mathbb{H C}$ assay of each mouse brain tissue are shown as scattered plots. Data are mean \pm SD. Student's t-test, ${ }^{\star \star} p<0.01$ compared with PBS. PeV-A3, parechovirus type 3; PBS, phosphatebuffered saline.

encephalitis- or sepsis-like diseases $(6,43-45)$. Despite accumulated clinical evidences of the pathovirulence of $\mathrm{PeV}-\mathrm{A} 3$, the pathogenic mechanisms of PeV-A3 infection remain unclear. Thus, to understand the infection of PeV-A3 in the CNS, this study used a clinically isolated $\mathrm{PeV}-\mathrm{A} 3$ strain to establish infection models in vitro and in vivo, with human neuronal cells (GBM and IMR-32) and C57BL/6 neonatal mice, respectively. Results showed that PeVA3 induced cell damages and triggered expression of inflammatory cytokines along with activation of death signaling pathways of apoptosis, autophagy, and pyroptosis. In the in vivo neonatal mouse model, the PeV-A3-infected mice showed body weight loss and CNS disease symptoms, such as limb weakness or paralysis, with approximately $20 \%$ mortality. PeV-A3 infection in the hippocampus and cortex regions was detected. PeV-A3 replication, inflammatory cytokine expression, and cell death signal activation were demonstrated in the mouse brain tissue. These results obtained in neonatal mice might partly interpret the pathogenesis of PeV-A3 (46).

Type I and type III IFN responses play a pivotal role in host antiviral machinery; they elicit expression of cellular antiviral proteins to restrict virus replication (35). The present in vitro infection models revealed that $\mathrm{PeV}-\mathrm{A} 3$ infection evoked a cellular type I and type III IFN antiviral activity and inflammatory response in GBM and IMR-32 cells. These findings echoed prior transcriptome analysis results of robust immune and inflammatory responses triggered by PeV-A3 in airway epithelial cells (47). On the other hand, type I IFN treatment can inhibit $\mathrm{PeV}-\mathrm{A} 3$ in neuronal cells, suggesting the $\mathrm{PeV}-\mathrm{A} 3$ susceptibility of PeV-A3 to extracellular IFN treatment. The potential role of TLR in neuron injury by $\mathrm{PeV}-\mathrm{A} 3$ infection was suggested (48); therefore, the expression of IFN genes and TLR-related pathway may act together to counteract PeV-A3 infection $(49,50)$.

Nevertheless, these endogenous antiviral responses seem unable to protect cells from PeV-A3-caused CPE. PeV-A3 might develop certain uncharacterized strategy to evade cellular IFN responses as other picornaviruses act $(40,51,52)$. For example, a previous study showed that PeV-A1 induced interferon regulatory factor 3 (IRF3) phosphorylation and type I IFN production and STAT1/2 activation in airway cell type but 

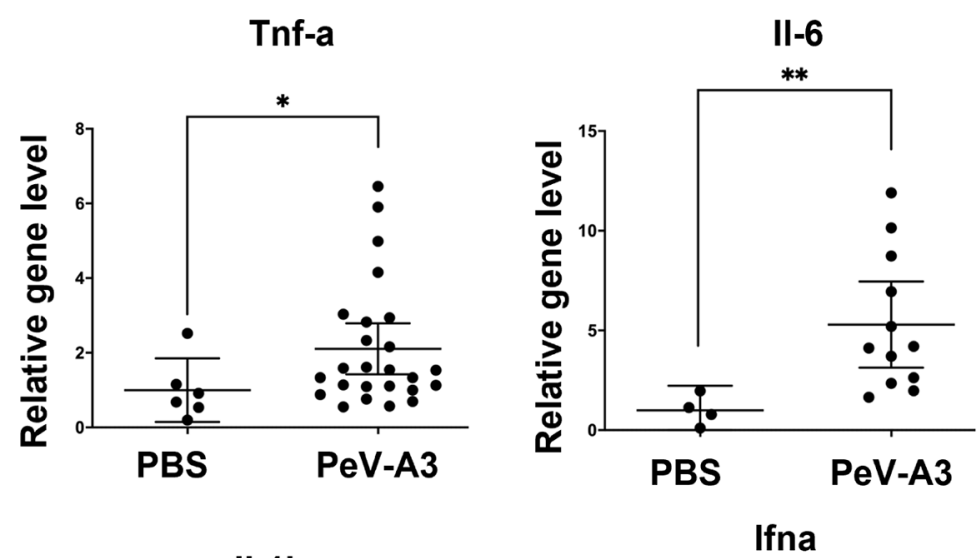

II-18
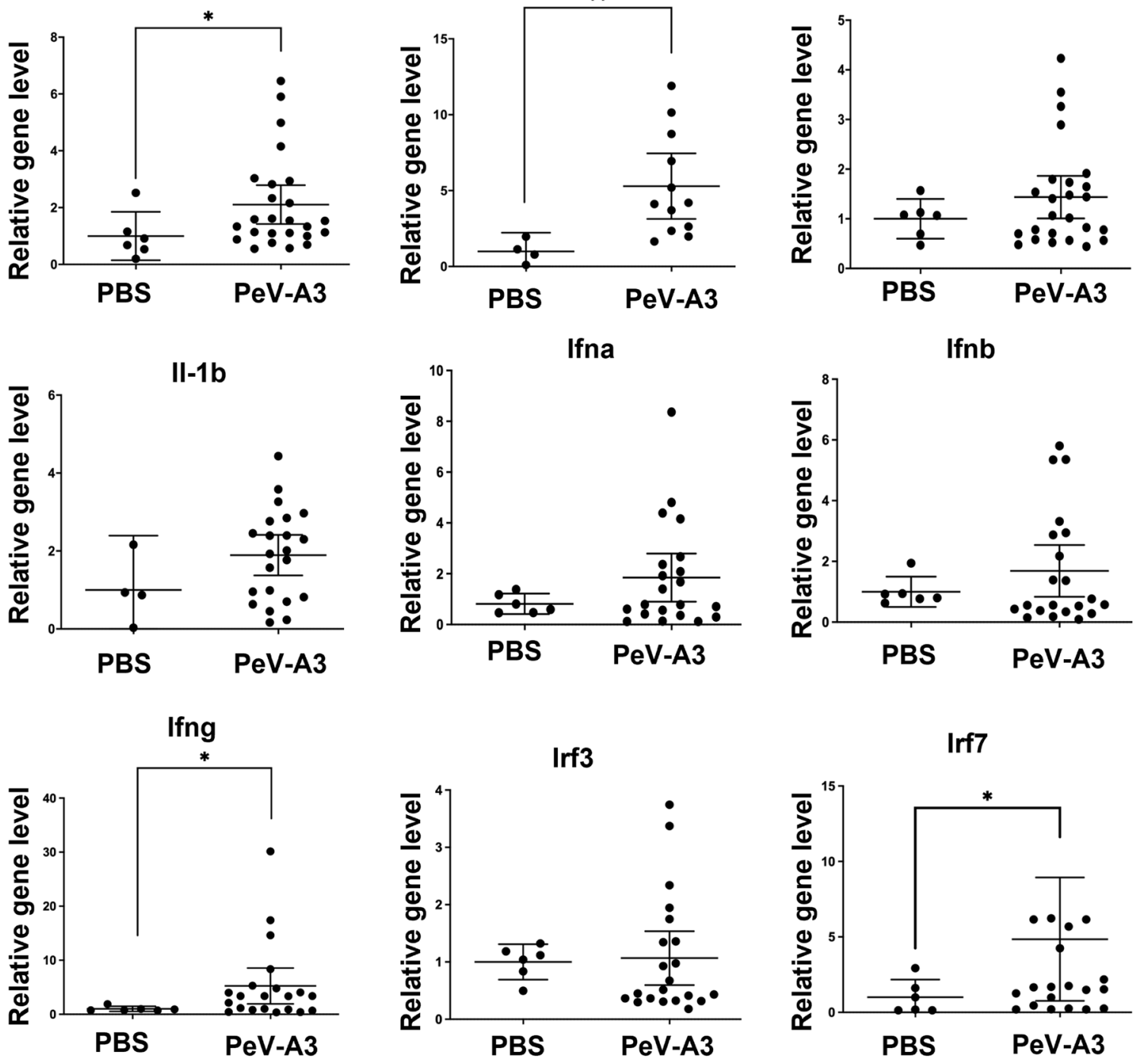

\section{Viperin}

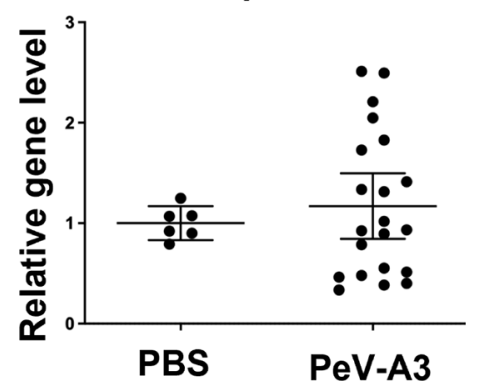

TIr3

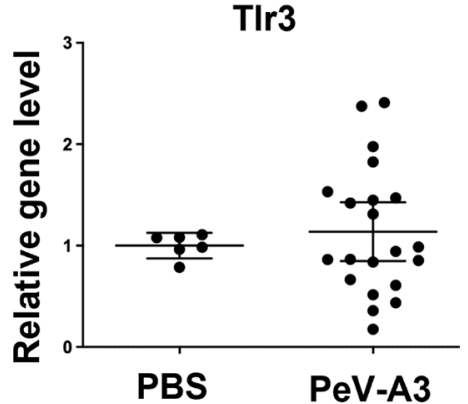

FIGURE 8 | PeV-A3 induced inflammatory cytokine expression and signal transduction in mouse brain tissues. mRNA expression of inflammatory cytokines (Tnfa, II6, II-8, and II-1b) and interferon signature genes (Ifna, Ifnb Ifng Irf3, IIf7, Viprin, and TIr3) in PeV-A3-infected C57BL/6 mouse brain tissues were measured and normalized using HPRT. Data are mean \pm SD, PBS group, $N=4-6$, PeV-A3 group, $N=12-25$. Independent two-sample t-test, ${ }^{*} p<0.05$; ${ }^{* \star} p<0.01$ compared with PBS. PeV-A3, parechovirus type 3; PBS, phosphate-buffered saline. 
A

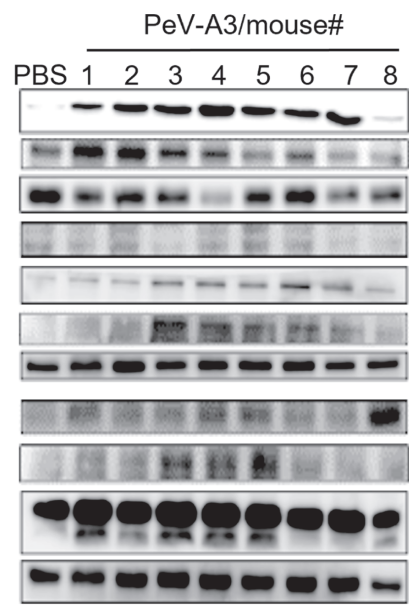

PeV-A3/mouse\#

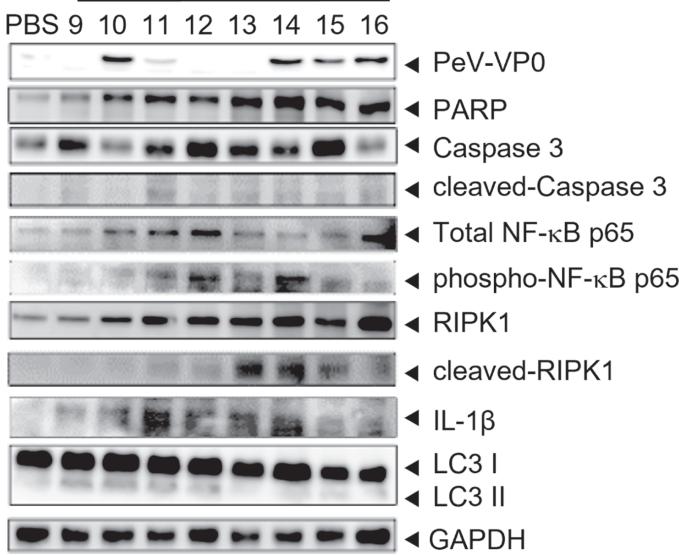

B
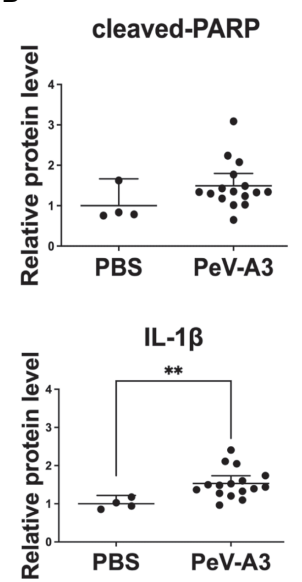

cleaved-Caspase 3

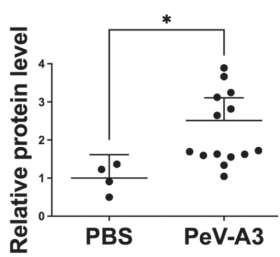

LC3 I

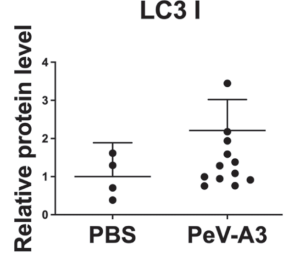

phospho-NF-KB p65
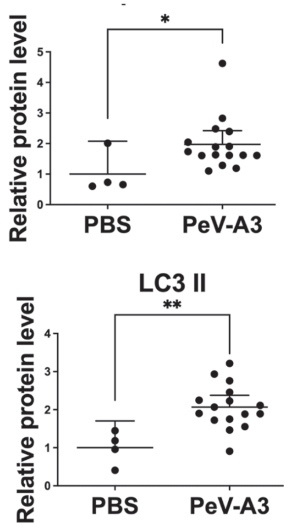

cleaved-RIPK1

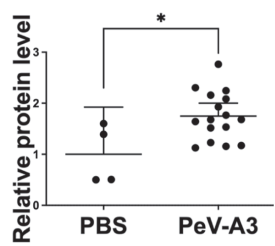

PeV-A3

FIGURE 9 | PeV-A3 induced signal transduction proteins in mouse brain tissues. (A) Immunoblotting of PARP, caspase 3, LC3, phospho-NF-kB p65 (Ser536), IL$1 \beta$, and RIPK1 in two PBS control and 16 PeV-A3 mouse brain tissues (\#1-\#16). (B) Quantification of protein expression level of PeV-A3-infected mice and PBS mock controls. Data are mean \pm SD, PBS group $N=4$, PeV-A3 group $N=16$. Independent two-sample t-test, ${ }^{*} p<0.05{ }^{* *} p<0.01$ compared with PBS mock controls. PeV-A3, parechovirus type 3; PBS, phosphate-buffered saline.

not in intestinal cells $(29,53)$. Thus, the interplay between PeVA3 and host antiviral activity merits further investigation.

The present results showed that PeV-A3 caused CPE in cells and induced death signaling activation and inflammatory responses in vitro and in vivo. Autophagy and pyroptosis are two types of programming cell death pathways accompanied with inflammatory responses $(41,54)$ that could be induced by $\mathrm{PeV}-\mathrm{A} 3$ infection. This finding is also consistent with findings on other picornaviruses, such as Aichi virus, foot-and-mouth disease virus (FMDV), rhinovirus, enterovirus 71 (EV71), or coxsackievirus B3. Of note is that the infection-mediated autophagy and pyroptosis activation play different roles in promoting/limiting viral replication or antiviral interferon response regulation (40,55-61). Thus, the effect of apoptosis, autophagy, and pyroptosis on $\mathrm{PeV}-\mathrm{A} 3$ replication or antiviral immune regulation should be further explored in the future.
$\mathrm{PeV}-\mathrm{A} 3$ has emerged as a neuroinvasive virus. Clinical evidences revealed that $\mathrm{PeV}-\mathrm{A} 3$ induced innate immune responses of cytokine/chemokine expression in neonates and infants (62). However, there was no suitable animal model for understanding neonatal PeV-A3 (26). This study put forward the first neonatal infection animal model established for exploring $\mathrm{PeV}-\mathrm{A} 3$ neuropathogenesis. In our model, we found the PeV-A3 infection in the hippocampus and cortex regions of the neonatal mouse brain. Results obtained using the model supported the clinical finding of innate inflammation response. Moreover, mechanistic analysis results revealed different cell death signaling pathways triggered by $\mathrm{PeV}-\mathrm{A} 3$ in mice. This established $\mathrm{PeV}-\mathrm{A} 3$ infection model would be useful for understanding the viral disease mechanism, which would in turn facilitate the development of effective prevention and treatment methods. 
In addition to the PeV-A3 infection animal model in this study, other picornavirus infection animal models were previously established in mice to address critical issues. For example, the pathogenic mechanism of echovirus was revealed in the transgenic mice with human integrin very late antigen 2 (VLA-2, echovirus entry receptor) expression. In an intracerebral inoculation of echovirus in VLA-2 newborn mice, the mice showed paralysis and wasting (63). Compared with the echovirus infection animal model, although PeV-A3 entry receptor was not identified, we found that PeV-A3 could directly infect human cells and C57BL/6 mouse brain, suggesting that $\mathrm{PeV}-\mathrm{A} 3$ infection may use a similar existing entry mechanism in different mammals. However, this hypothesis needs to be confirmed with further studies. EV71 is another neuropathic picornavirus. Two EV71 disease mouse models have been established before. One model used mouse-adaptive EV71 to infect 1-day-old Institute of Cancer Research (ICR) mice (64); the other used non-mouse adaptive EV71 to infect 3-day-old to 2-week-old AG129 mice (deficient in interferon alpha/beta and gamma receptor signaling) (65). Both studies revealed 100\% mortality for intraperitoneal infection with EV71. However, this present study observed only $20 \%$ mortality in PeV-A3-infected newborn C57BL/6 mice. Such discrepancy may be attributed to viral virulence and mouse strain used. Contrary to using mouse-adapted EV71 strain or type I IFN activity-deficient mice, this study employed clinically isolated PeV-A3 to challenge immunocompetent mice, with induction of host IFN activity providing certain protection activity. In addition, oral infection of EV71 causing the disease in mice was also demonstrated $(64,65)$.

Although PeV-A3 infection was presumed to be fecal-oral and respiratory routes (9), direct evidence supporting PeV-A3 transmission via fecal-oral route is lacking (66). Thus, this study adapted the previously reported echovirus infection method (63), with PeV-A3 intracerebrally inoculated into newborn mice. Intrafamilial transmission of $\mathrm{PeV}-\mathrm{A}$ and enteroviruses in neonates and young infants seems to be critical for spreading virus; hence, using different methods of viral inoculation to mimic PeV-A3 infections for further study would be of interest (67).

This study showed that type I IFN treatment was able to activate host innate immunity against $\mathrm{PeV}-\mathrm{A} 3$ in vitro. Although this treatment was not administered in this study, similar results were expected for EV71, whose infection and replication in mice, though rare, were potently controlled by type I IFN (68). Except for the biologics treatment, the in vitro-identified small compounds or drugs against picornavirus need to be evaluated in vivo (69). The proposed $\mathrm{PeV}-\mathrm{A} 3$ animal model would serve as a useful platform to evaluate the efficacy of antiviral compounds.

\section{CONCLUSION}

This study successfully deciphered neuropathogenic mechanisms of PeV-A3 in human neuronal cells and in neonatal mice. PeVA3-induced neuronal cell death-associated inflammation may play important roles in disease onset. The present findings enable better understanding of the characteristics and fundamental infection features of PeV-A3 in the neuronal system, which would contribute to the development of prevention or treatment method of $\mathrm{PeV}-\mathrm{A} 3$ infection.

\section{DATA AVAILABILITY STATEMENT}

The original contributions presented in the study are included in the article/Supplementary Material. Further inquiries can be directed to the corresponding authors.

\section{ETHICS STATEMENT}

The animal study was reviewed and approved by the Institutional Animal Care and Use Committee or Panel (IACUC) in Kaohsiung Veterans General Hospital, Taiwan (IACUC Approval No. VGHKS-2018-2021-A016).

\section{AUTHOR CONTRIBUTIONS}

Conceptualization: T-HC. Methodology: M-WJ, H-LS, T-HC, and KJT. Validation: T-HC and KJT. Formal analysis: M-WJ. Investigation: M-WJ, T-HC, and H-LS. Data curation: M-WJ, T$\mathrm{HC}$, and K-T. Writing-original draft preparation: M-WJ and T-HC. Writing-review and editing: H-LS, T-HC, and KJT. Supervision: T$\mathrm{HC}$ and K-T. Funding acquisition: T-HC. All authors contributed to the article and approved the submitted version.

\section{FUNDING}

This research was funded by the Ministry of Science and Technology of Taiwan, grant numbers MOST109-2320-B-016-013 and MOST110-2320-B-016-012, and by Kaohsiung Veterans General Hospital, grant numbers VGHKS107-170 and VGHKS 107-G02. The funders had no role in study design, data collection and analysis, decision to publish, or preparation of the manuscript.

\section{ACKNOWLEDGMENTS}

We thank Yao-Shen Chen and Bao-Chen Chen (Kaohsiung Veterans General Hospital) for their technical assistance.

\section{SUPPLEMENTARY MATERIAL}

The Supplementary Material for this article can be found online at: https://www.frontiersin.org/articles/10.3389/fimmu.2021. 753683/full\#supplementary-material

Supplementary Figure 1 | The panel of RT2 array.

Supplementary Figure 2 | Cell death signaling analysis in PeV-A3 infected IMR32 cells. 


\section{REFERENCES}

1. Nateri AS, Hughes PJ, Stanway G. In Vivo and In Vitro Identification of Structural and Sequence Elements of the Human Parechovirus 5' Untranslated Region Required for Internal Initiation. J Virol (2000) 74:6269-77. doi: 10.1128/JVI.74.14.6269-6277.2000

2. Wigand R, Sabin AB. Properties of ECHO Types 22, 23 and 24 Viruses. Arch Gesamte Virusforsch (1961) 11:224-47. doi: 10.1007/BF01241688

3. Ghazi F, Hughes PJ, Hyypia T, Stanway G. Molecular Analysis of Human Parechovirus Type 2 (Formerly Echovirus 23). J Gen Virol (1998) 79(Pt 11):2641-50. doi: 10.1099/0022-1317-79-11-2641

4. Hyypia T, Horsnell C, Maaronen M, Khan M, Kalkkinen N, Auvinen P, et al. A Distinct Picornavirus Group Identified by Sequence Analysis. Proc Natl Acad Sci U.S.A. (1992) 89:8847-51. doi: 10.1073/pnas.89.18.8847

5. Stanway G, Kalkkinen N, Roivainen M, Ghazi F, Khan M, Smyth M, et al. Molecular and Biological Characteristics of Echovirus 22, a Representative of a New Picornavirus Group. J Virol (1994) 68:8232-8. doi: 10.1128/ jvi.68.12.8232-8238.1994

6. Olijve L, Jennings L, Walls T. Human Parechovirus: An Increasingly Recognized Cause of Sepsis-Like Illness in Young Infants. Clin Microbiol Rev (2018) 31:1-17. doi: 10.1128/CMR.00047-17

7. Britton PN, Jones CA, Macartney K, Cheng AC. Parechovirus: An Important Emerging Infection in Young Infants. Med J Aust (2018) 208:365-9. doi: $10.5694 / \mathrm{mja} 18.00149$

8. Mizuta K, Aoki Y, Komabayashi K, Ikeda T. Proposal for the Recognition of a New Disease Concept From Japan; Parechovirus A3-Associated Myalgia. Jpn J Infect Dis (2020) 74:259-72. doi: 10.7883/yoken. JJID.2020.967

9. Benschop K, Minnaar R, Koen G, van Eijk H, Dijkman K, Westerhuis B, et al. Detection of Human Enterovirus and Human Parechovirus (Hpev) Genotypes From Clinical Stool Samples: Polymerase Chain Reaction and Direct Molecular Typing, Culture Characteristics, and Serotyping. Diagn Microbiol Infect Dis (2010) 68:166-73. doi: 10.1016/j.diagmicrobio.2010.05.016

10. Chen BC, Chang JT, Huang TS, Chen JJ, Chen YS, Jan MW, et al. Parechovirus a Detection by a Comprehensive Approach in a Clinical Laboratory. Viruses (2018) 10(12):711. doi: 10.3390/v10120711

11. Verboon-Maciolek MA, Utrecht FG, Cowan F, Govaert P, van Loon AM, de Vries LS. White Matter Damage in Neonatal Enterovirus Meningoencephalitis. Neurology (2008) 71:536. doi: 10.1212/01.wnl.0000324706.94229.88

12. Lane LM, McDermott MB, O'Connor P, Cronly S, O'Regan M, De Gascun CF, et al. Multicystic Encephalomalacia: The Neuropathology of Systemic Neonatal Parechovirus Infection. Pediatr Dev Pathol (2021) 24:460-6. doi: $10.1177 / 10935266211001645$

13. Ghanem-Zoubi N, Shiner M, Shulman LM, Sofer D, Wolf D, Marva E, et al. Human Parechovirus Type 3 Central Nervous System Infections in Israeli Infants. J Clin Virol (2013) 58:205-10. doi: 10.1016/j.jcv.2013.06.001

14. Sasidharan A, Banerjee D, Harrison CJ, Selvarangan R. Emergence of Parechovirus-A3 as the Leading Cause of Central Nervous System Infection Surpassing Any Single Enterovirus Type in Children in Kansas City, USA From 2007-2016. J Clin Microbiol (2021) 59:e02935-20. doi: 10.1128/ JCM.02935-20

15. Westerhuis BM, Koen G, Wildenbeest JG, Pajkrt D, de Jong MD, Benschop KS, et al. Specific Cell Tropism and Neutralization of Human Parechovirus Types 1 and 3: Implications for Pathogenesis and Therapy Development. J Gen Virol (2012) 93:2363-70. doi: 10.1099/vir.0.043323-0

16. van Hinsbergh TMT, Elbers RG, Hans Ket JCF, van Furth AM, Obihara CC. Neurological and Neurodevelopmental Outcomes After Human Parechovirus CNS Infection in Neonates and Young Children: A Systematic Review and Meta-Analysis. Lancet Child Adolesc Health (2020) 4:592-605. doi: 10.1016/ S2352-4642(20)30181-4

17. Triantafilou K, Triantafilou M, Takada Y, Fernandez N. Human Parechovirus 1 Utilizes Integrins Alphavbeta3 and Alphavbeta1 as Receptors. J Virol (2000) 74:5856-62. doi: 10.1128/JVI.74.13.5856-5862.2000

18. Merilahti P, Karelehto E, Susi P. Role of Heparan Sulfate in Cellular Infection of Integrin-Binding Coxsackievirus A9 and Human Parechovirus 1 Isolates. PloS One (2016) 11:e0147168. doi: 10.1371/journal.pone.0147168

19. Benschop KS, Williams CH, Wolthers KC, Stanway G, Simmonds P. Widespread Recombination Within Human Parechoviruses: Analysis of
Temporal Dynamics and Constraints. J Gen Virol (2008) 89:1030-5. doi: 10.1099/vir.0.83498-0

20. Harvala H, Robertson I, Chieochansin T, McWilliam Leitch EC, Templeton K, Simmonds P. Specific Association of Human Parechovirus Type 3 With Sepsis and Fever in Young Infants, as Identified by Direct Typing of Cerebrospinal Fluid Samples. J Infect Dis (2009) 199:1753-60. doi: 10.1086/599094

21. Kroemer G, Galluzzi L, Vandenabeele P, Abrams J, Alnemri ES, Baehrecke $\mathrm{EH}$, et al. Classification of Cell Death: Recommendations of the Nomenclature Committee on Cell Death 2009. Cell Death Differ (2009) 16:3-11. doi: 10.1038/ cdd.2008.150

22. Kofahi HM, Taylor NG, Hirasawa K, Grant MD, Russell RS. Hepatitis C Virus Infection of Cultured Human Hepatoma Cells Causes Apoptosis and Pyroptosis in Both Infected and Bystander Cells. Sci Rep (2016) 6:37433. doi: $10.1038 /$ srep37433

23. Danthi P. Viruses and the Diversity of Cell Death. Annu Rev Virol (2016) 3:533-53. doi: 10.1146/annurev-virology-110615-042435

24. Neumann S, El Maadidi S, Faletti L, Haun F, Labib S, Schejtman A, et al. How do Viruses Control Mitochondria-Mediated Apoptosis? Virus Res (2015) 209:45-55. doi: 10.1016/j.virusres.2015.02.026

25. Perera N, Miller JL, Zitzmann N. The Role of the Unfolded Protein Response in Dengue Virus Pathogenesis. Cell Microbiol (2017) 19:e12734. doi: 10.1111/cmi.12734

26. Sridhar A, Karelehto E, Brouwer L, Pajkrt D, Wolthers KC. Parechovirus a Pathogenesis and the Enigma of Genotype a-3. Viruses (2019) 11:1062. doi: 10.3390/v11111062

27. Chen BC, Cheng MF, Huang TS, Liu YC, Tang CW, Chen CS, et al. Detection and Identification of Human Parechoviruses From Clinical Specimens. Diagn Microbiol Infect Dis (2009) 65:254-60. doi: 10.1016/j.diagmicrobio.2009.07.014

28. Chang JT, Yang CS, Chen BC, Chen YS, Chang TH. Complete Genome Sequence of the First Human Parechovirus Type 3 Isolated in Taiwan. J Chin Med Assoc (2017) 80:737-9. doi: 10.1016/j.jcma.2017.07.007

29. Chang JT, Yang CS, Chen YS, Chen BC, Chiang AJ, Chang YH, et al. Genome and Infection Characteristics of Human Parechovirus Type 1: The Interplay Between Viral Infection and Type I Interferon Antiviral System. PloS One (2015) 10:e0116158. doi: 10.1371/journal.pone.0116158

30. Kim JY, Ash RT, Ceballos-Diaz C, Levites Y, Golde TE, Smirnakis SM, et al. Viral Transduction of the Neonatal Brain Delivers Controllable Genetic Mosaicism for Visualising and Manipulating Neuronal Circuits In Vivo. Eur J Neurosci (2013) 37:1203-20. doi: 10.1111/ejn.12126

31. Mazar J, Li Y, Rosado A, Phelan P, Kedarinath K, Parks GD, et al. Zika Virus as an Oncolytic Treatment of Human Neuroblastoma Cells Requires CD24. PloS One (2018) 13:e0200358. doi: 10.1371/journal.pone.0200358

32. Zhu Z, Mesci P, Bernatchez JA, Gimple RC, Wang X, Schafer ST, et al. Zika Virus Targets Glioblastoma Stem Cells Through a SOX2-Integrin Alphavbeta5 Axis. Cell Stem Cell (2020) 26:187-204.e10. doi: 10.1016/ j.stem.2019.11.016

33. Xu LJ, Jiang T, Zhang FJ, Han JF, Liu J, Zhao H, et al. Global Transcriptomic Analysis of Human Neuroblastoma Cells in Response to Enterovirus Type 71 Infection. PloS One (2013) 8:e65948. doi: 10.1371/journal.pone.0065948

34. Shih SR, Weng KF, Stollar V, Li ML. Viral Protein Synthesis is Required for Enterovirus 71 to Induce Apoptosis in Human Glioblastoma Cells. J Neurovirol (2008) 14:53-61. doi: 10.1080/13550280701798980

35. Mesev EV, LeDesma RA, Ploss A, Decoding type I. And III Interferon Signalling During Viral Infection. Nat Microbiol (2019) 4:914-24. doi: 10.1038/s41564-019-0421-x

36. Ishibashi D, Homma T, Nakagaki T, Fuse T, Sano K, Satoh K, et al. Type I Interferon Protects Neurons From Prions in In Vivo Models. Brain (2019) 142:1035-50. doi: 10.1093/brain/awz016

37. Ahmad L, Mostowy S, Sancho-Shimizu V. Autophagy-Virus Interplay: From Cell Biology to Human Disease. Front Cell Dev Biol (2018) 6:155. doi: 10.3389/ fcell.2018.00155

38. Denton D, Kumar S. Autophagy-Dependent Cell Death. Cell Death Differ (2019) 26:605-16. doi: 10.1038/s41418-018-0252-y

39. Criollo A, Chereau F, Malik SA, Niso-Santano M, Marino G, Galluzzi L, et al. Autophagy is Required for the Activation of Nfkappab. Cell Cycle (2012) 11:194-9. doi: 10.4161/cc.11.1.18669

40. Kung MH, Lin YS, Chang TH. Aichi Virus 3C Protease Modulates LC3- and SQSTM1/P62-Involved Antiviral Response. Theranostics (2020) 10:9200-13. doi: $10.7150 /$ thno.47077 
41. Bergsbaken T, Fink SL, Cookson BT. Pyroptosis: Host Cell Death and Inflammation. Nat Rev Microbiol (2009) 7:99-109. doi: 10.1038/nrmicro2070

42. Swanson KV, Deng M, Ting JP. The NLRP3 Inflammasome: Molecular Activation and Regulation to Therapeutics. Nat Rev Immunol (2019) 19:477-89. doi: 10.1038/s41577-019-0165-0

43. Kadambari S, Braccio S, Ribeiro S, Allen DJ, Pebody R, Brown D, et al. Enterovirus and Parechovirus Meningitis in Infants Younger Than 90 Days Old in the UK and Republic of Ireland: A British Paediatric Surveillance Unit Study. Arch Dis Child (2019) 104:552-7. doi: 10.1136/archdischild-2018-315643

44. Bissel SJ, Auer RN, Chiang CH, Kofler J, Murdoch GH, Nix WA, et al. Human Parechovirus 3 Meningitis and Fatal Leukoencephalopathy. J Neuropathol Exp Neurol (2015) 74:767-77. doi: 10.1097/NEN.0000000000000215

45. Wolthers KC, Benschop KS, Schinkel J, Molenkamp R, Bergevoet RM, Spijkerman IJ, et al. Human Parechoviruses as an Important Viral Cause of Sepsislike Illness and Meningitis in Young Children. Clin Infect Dis (2008) 47:358-63. doi: 10.1086/589752

46. Watanabe K, Hirokawa C, Tazawa T. Seropositivity and Epidemiology of Human Parechovirus Types 1, 3, and 6 in Japan. Epidemiol Infect (2016) 144:3451-60. doi: 10.1017/S0950268816001795

47. Karelehto E, Cristella C, Yu X, Sridhar A, Hulsdouw R, de Haan K, et al. Polarized Entry of Human Parechoviruses in the Airway Epithelium. Front Cell Infect Microbiol (2018) 8:294. doi: 10.3389/fcimb.2018.00294

48. Volpe JJ. Neonatal Encephalitis and White Matter Injury: More Than Just Inflammation? Ann Neurol (2008) 64:232-6. doi: 10.1002/ana.21466

49. Hiscott J, Grandvaux N, Sharma S, Tenoever BR, Servant MJ, Lin R. Convergence of the NF-Kappab and Interferon Signaling Pathways in the Regulation of Antiviral Defense and Apoptosis. Ann N Y Acad Sci (2003) 1010:237-48. doi: 10.1196/annals.1299.042

50. Triantafilou K, Vakakis E, Orthopoulos G, Ahmed MA, Schumann C, Lepper PM, et al. TLR8 and TLR7 are Involved in the Host's Immune Response to Human Parechovirus 1. Eur J Immunol (2005) 35:2416-23. doi: 10.1002/ eji.200526149

51. Garcia-Sastre A. Ten Strategies of Interferon Evasion by Viruses. Cell Host Microbe (2017) 22:176-84. doi: 10.1016/j.chom.2017.07.012

52. Zhang $\mathrm{X}$, Paget $\mathrm{M}$, Wang $\mathrm{C}$, Zhu Z, Zheng H. Innate Immune Evasion by Picornaviruses. Eur J Immunol (2020) 50:1268-82. doi: 10.1002/eji.202048785

53. Lin TH, Cheng CC, Su HH, Huang NC, Chen JJ, Kang HY, et al. Lipopolysaccharide Attenuates Induction of Proallergic Cytokines, Thymic Stromal Lymphopoietin, and Interleukin 33 in Respiratory Epithelial Cells Stimulated With Polyi:C and Human Parechovirus. Front Immunol (2016) 7:440. doi: 10.3389/fimmu.2016.00440

54. Deretic V. Autophagy in Inflammation, Infection, and Immunometabolism. Immunity (2021) 54:437-53. doi: 10.1016/j.immuni.2021.01.018

55. Lin JY, Huang HI. Autophagy is Induced and Supports Virus Replication in Enterovirus A71-Infected Human Primary Neuronal Cells. Sci Rep (2020) 10:15234. doi: 10.1038/s41598-020-71970-3

56. Ranjitha HB, Ammanathan V, Guleria N, Hosamani M, Sreenivasa BP, Dhanesh VV, et al. Foot-and-Mouth Disease Virus Induces PERK-Mediated Autophagy to Suppress the Antiviral Interferon Response. J Cell Sci (2020) 134 (5):jcs240622. doi: $10.1242 /$ jcs. 240622

57. Wang B, Zhu Y, Liu L, Wang B, Chen M, Wang J, et al. Enterovirus 71 Induces Autophagy in Mice via mTOR Inhibition and ERK Pathway Activation. Life Sci (2021) 271:119188. doi: 10.1016/j.lfs.2021.119188

58. Wang Y, Qin Y, Wang T, Chen Y, Lang X, Zheng J, et al. Pyroptosis Induced by Enterovirus 71 and Coxsackievirus B3 Infection Affects Viral Replication and Host Response. Sci Rep (2018) 8:2887. doi: 10.1038/s41598-018-20958-1
59. Liu T, Zhou YT, Wang LQ, Li LY, Bao Q, Tian S, et al. NOD-Like Receptor Family, Pyrin Domain Containing 3 (NLRP3) Contributes to Inflammation, Pyroptosis, and Mucin Production in Human Airway Epithelium on Rhinovirus Infection. J Allergy Clin Immunol (2019) 144:777-787 e9. doi: 10.1016/j.jaci.2019.05.006

60. Zhu X, Wu T, Chi Y, Ge Y, Wu B, Zhou M, et al. Pyroptosis Induced by Enterovirus A71 Infection in Cultured Human Neuroblastoma Cells. Virology (2018) 521:69-76. doi: 10.1016/j.virol.2018.05.025

61. Imre G. Cell Death Signalling in Virus Infection. Cell Signal (2020) 76:109772. doi: 10.1016/j.cellsig.2020.109772

62. Habuka R, Aizawa Y, Izumita R, Domon H, Terao Y, Takihara H, et al. Innate Immune Responses in Serum and Cerebrospinal Fluid From Neonates and Infants Infected With Parechovirus-A3 or Enteroviruses. J Infect Dis (2020) 222:681-9. doi: 10.1093/infdis/jiaal31

63. Hughes SA, Thaker HM, Racaniello VR. Transgenic Mouse Model for Echovirus Myocarditis and Paralysis. Proc Natl Acad Sci USA (2003) 100:15906-11. doi: 10.1073/pnas.2535934100

64. Wang YF, Chou CT, Lei HY, Liu CC, Wang SM, Yan JJ, et al. A MouseAdapted Enterovirus 71 Strain Causes Neurological Disease in Mice After Oral Infection. J Virol (2004) 78:7916-24. doi: 10.1128/JVI.78.15.79167924.2004

65. Khong WX, Yan B, Yeo H, Tan EL, Lee JJ, Ng JK, et al. A non-Mouse-Adapted Enterovirus 71 (EV71) Strain Exhibits Neurotropism, Causing Neurological Manifestations in a Novel Mouse Model of EV71 Infection. J Virol (2012) 86:2121-31. doi: 10.1128/JVI.06103-11

66. Aizawa Y, Yamanaka T, Watanabe K, Oishi T, Saitoh A. Asymptomatic Children Might Transmit Human Parechovirus Type 3 to Neonates and Young Infants. J Clin Virol (2015) 70:105-8. doi: 10.1016/j.jcv.2015.07.300

67. Izumita R, Deuchi K, Aizawa Y, Habuka R, Watanabe K, Otsuka T, et al. Intrafamilial Transmission of Parechovirus a and Enteroviruses in Neonates and Young Infants. J Pediatr Infect Dis Soc (2019) 8:501-6. doi: 10.1093/jpids/ piy079

68. Liu ML, Lee YP, Wang YF, Lei HY, Liu CC, Wang SM, et al. Type I Interferons Protect Mice Against Enterovirus 71 Infection. J Gen Virol (2005) 86:3263-9. doi: 10.1099/vir.0.81195-0

69. Ford Siltz LA, Viktorova EG, Zhang B, Kouiavskaia D, Dragunsky E, Chumakov K, et al. New Small-Molecule Inhibitors Effectively Blocking Picornavirus Replication. J Virol (2014) 88:11091-107. doi: 10.1128/ JVI.01877-14

Conflict of Interest: The authors declare that the research was conducted in the absence of any commercial or financial relationships that could be construed as a potential conflict of interest.

Publisher's Note: All claims expressed in this article are solely those of the authors and do not necessarily represent those of their affiliated organizations, or those of the publisher, the editors and the reviewers. Any product that may be evaluated in this article, or claim that may be made by its manufacturer, is not guaranteed or endorsed by the publisher.

Copyright $\odot 2021$ Jan, Su, Chang and Tsai. This is an open-access article distributed under the terms of the Creative Commons Attribution License (CC BY). The use, distribution or reproduction in other forums is permitted, provided the original author(s) and the copyright owner(s) are credited and that the original publication in this journal is cited, in accordance with accepted academic practice. No use, distribution or reproduction is permitted which does not comply with these terms. 